\title{
Optimising feed-in tariff design through efficient risk allocation
}

\author{
Mel T. Devine $e^{\mathrm{a}, \mathrm{b}, \mathrm{c}, *}$, Niall Farrell ${ }^{\mathrm{b}, \mathrm{c}}$, William Lee $\mathrm{e}^{\mathrm{a}}$ \\ ${ }^{a}$ MACSI, Department of Mathematics and Statistics, University of Limerick, Limerick, Ireland \\ ${ }^{b}$ Economic and Social Research Institute, Whitaker Square, Sir John Rogerson's Quay, Dublin, Ireland \\ ${ }^{c}$ Department of Economics, Trinity College, Dublin, Ireland
}

\begin{abstract}
Many Feed-in Tariff designs exist. This paper provides a framework to determine the optimal design choice through an efficient allocation of market price risk. Feed-in Tariffs (FiTs) incentivise the deployment of renewable energy technologies by subsidising remuneration and transferring market price risk from investors, through policymakers, to a counterparty. This counterparty is often the electricity consumer. Using Stackelberg game theory, we contextualise the application of different FiT policy designs that efficiently divide market price risk between investors and consumers, conditional on risk preferences and market conditions. Explicit consideration of policymaker/consumer risk burden has not been incorporated in FiT analyses to date. We present a simulation-based modelling framework to carry this out. Through an Irish case study, we find that commonly employed flat-rate FiTs are only optimal when policymaker risk aversion is extremely low whilst constant premium policies are only optimal when investor risk aversion is extremely low. When both policymakers and investors are risk averse, an intermediate division of risk is optimal. We provide evidence to suggest that the contextual application of many FiT structures is suboptimal, assuming both investors and policymakers are at least moderately risk averse. Efficient risk allocation in FiT design choice will be of increasing policy importance as renewables deployment grows.
\end{abstract}

Keywords: Renewable Energy, Feed-in Tariff, Bi-level model, Renewable Support Schemes, Market Price Risk

\footnotetext{
*Corresponding author: Mel Devine

Email addresses: mel.devine@esri.ie (Mel T. Devine), niallfarrell@gmail.com (Niall Farrell), william.lee@ul.ie (William Lee)
} 


\section{Introduction}

The intermittent nature of many renewable energy sources combine with uncertain market prices to make renewable energy investment an inherently risky venture. Feed-in Tariffs (FiTs) guarantee a set payment per unit of electricity generated and thus limit investors' exposure to low market prices to a greater extent than alternate mechanisms (Burer and Wustenhagen, 2009; Haas et al., 2011; IEA and OECD, 2008; Ragwitz et al., 2007; Fagiani et al., 2013). Although theoretically less efficient than quantity-based schemes (Ringel, 2006), FiTs have become a preferred policy mechanism for many jurisdictions as the reduced exposure to market price risk has incentivised greater deployment of renewable technologies (Menanteau et al., 2003; Haas et al., 2011).

FiTs do not eliminate market price risk but rather transfer this risk to a counterparty. This counterparty bears the risk of additional policy cost if wholesale prices are less than the FiT guarantee. Often, a policymaker incurs this aggregate risk in the first instance, which is then transferred to electricity consumers through additional charges on consumption (Farrell and Lyons, 2015; Gross et al., 2010). Different FiT designs apportion this risk in different ways (Couture and Gagnon, 2010; Kim and Lee, 2012), with zero, partial or full transfer of market price risk possible (Farrell et al., 2017). Although the literature has acknowledged that appropriate risk transfer is central to successful renewables policy (Klessmann et al., 2013), the optimal division of risk has not been analysed.

Given both investor and policymaker aversion to market price risk, optimal policy design must efficiently divide this burden, analogous to the division of risk central to the design of insurance contracts (Raviv, 1979). This paper presents a simulation-based modelling framework to divide risk in a similar way. To carry this out, a characterisation of both investors' and policymaker's/consumers' attitude to market, regulatory and policy risks, and their reactions in different contexts, is required (Ekins, 2004; Gross et al., 2010). This is an important contribution, as while many policy designs have been implemented to date, the choice has not been guided towards the most efficient outcome through an appropriate objective framework. This framework is developed in this paper and applied to an Irish case study. This gives important policy insight as the impact of excessive consumer exposure to market price risk is becoming of increasing concern for FiT policy in many countries such as Ireland (Farrell and Lyons, 2015), Germany (Neuhoff et al., 2013), the UK (Chawla and Pollitt, 2013) and Italy (Verde and Pazienza, 2013).

\footnotetext{
Abbreviations: CARA: Constant Absolute Risk Aversion; CE: Certainty Equivalent; CfD: Contract for Difference; CRRA: Constant Relative Risk Aversion; EMV: Expected Money Value; FiT: Feed-in Tariff; IEA: International Energy Agency; MW: Megawatt; OECD: Organisation for Economic Cooperation and Development; O \& M: Operations \& Maintenance; REFIT: Renewable Energy Feed-in Tariff; ROC: Renewables Obligation Certificate; SEM: Single Electricity Market; VWAP: Volume-Weighted Average Price; CP: Constant Premium; SU: Shared Upside; CF: Cap \& Floor
} 
This paper is structured as follows. The following section will give a literature review. Section 3 will outline the methodology employed. Section 4 presents the data for a stylised Irish case study while Section 5 describes the results. Finally, Section 6 offers a discussion and conclusion.

\section{Literature Review and Motivation}

A considerable gap exists in the literature to provide a suitable policy tool to identify the optimal FiT design. Reviewing the literature in this field brings together literature focussing on investment incentives and consumer policy cost. Much of this analysis is from an investor's perspective and has compared investment incentives created by FiTs with those offered by alternate, non-FiT support mechanisms (Dong, 2012; Fagiani et al., 2013; Menanteau et al., 2003; Ragwitz et al., 2007; Ringel, 2006). The literature to date has found that FiTs have led to greater deployment than alternatives as investor exposure to market price risk is lower (Burer and Wustenhagen, 2009; Butler and Neuhoff, 2008; Kitzing, 2014; Falconett and Nagasaka, 2010). Indeed, exposure and attitude to risk is a key determinant in the superior effectiveness of FiT regimes. Comparing FiTs to quantity-based policies, Fagiani et al. (2013), Kitzing et al. (2012) and Kitzing (2014) have emphasised the importance of incorporating market price risk when deciding on the subsidy type (in particular, a FiT or quantity-based mechanism). Indeed, Dinica (2006) and Feng et al. (2012) elaborate on how the relationship between risk and profitability is key to encouraging investment.

While the preceding papers have stated the importance of considering risk for the superior effectiveness of FiT mechanisms, focussing on risk attitudes and investment incentives in optimal FiT design has received less attention in the literature. Kim and Lee (2012) have analysed FiT payout structures to incentivise Solar PV deployment. Kim and Lee (2012) incorporate network effects and the propensity to adopt household-based solar PV. However, they do not evaluate how different attiudes to market price risk may affect results. Doherty and O'Malley (2011) also focus on investors when analysing the efficiency of Ireland's FiT design. Although they suggest that the current Irish FiT over-remunerates investors, they do not compare FiT choice amongst efficiently specified options, nor do they consider consumer and investor attitidues to market price risk. Farrell et al. (2017) provide a model with which different FiT regimes may be efficiently defined using option pricing theory. For each design, cost and remuneration are equal in expectation. However, the balance of certain/uncertain policy cost and investor remuneration varies between policy options.

Although managing investor risk exposure has been found to be of great importance for optimal energy policy, less attention has been given to managing policymaker/consumer risk exposure. However, a body of literature exists to analyse trends in policymaker/consumer cost. Parkinson and Djilali (2015) discuss the issue of performance uncertainty of energy technologies with respect to pollution limitation, and the incorporation of policymaker risk aversion in prudent policy design. In an Australian context, Riesz et al. (2015) consider the risks of excessive policy cost associated 
with adopting high levels of gas penetration to abate carbon emissions. Leepa and Unfried (2013) discuss the impacts of overdeployment and how this may result in excessive consumer cost. Low market prices present a similar risk of excessive consumer cost in relation to FiT policies. Indeed, a greater penetration of renewables coupled with lower than expected fossil fuel cost has resulted in greater subsidies in recent years (Bryant, 2013; Chawla and Pollitt, 2013; DW, 2013; Farrell and Lyons, 2015; Loreck et al., 2012) with potential for this trend to continue (Batlle, 2011; Chawla and Pollitt, 2013; Devitt and Malaguzzi Valeri, 2011; Fagiani et al., 2013; Klessmann et al., 2013; Leepa and Unfried, 2013; Loreck et al., 2012). One can see that increasing policy cost is a consistent trend, with uncertainty regarding the extent of future policy cost (Devitt and Malaguzzi Valeri, 2011; Klessmann et al., 2013). Given that the setting of a FiT policy is carried out in a prospective manner, where future costs are uncertain, the incorporation of consumer burden and attitudes to risk of excessive policy cost is an important consideration.

Thus, it is important to correctly manage both investor and policymaker exposure to market price risk when designing renewables policy. Such management involves balancing a trade-off: removing one degree of market price risk from the investor requires the policymaker to bear an additional degree of risk. Precisely identifying the most efficient point in this trade-off has not been carried out by the literature to date.

Farrell et al. (2017) discuss the concept of risk-sharing when choosing between designs using a bi-level model similar to that considered in this work. In particular, they discuss the Valueat-Risk (VaR) associated with different policies ex-post any FiT level decisions made. However, when determining optimal FiT levels, they model both policymakers and investors as risk neutral players. Thus, in contrast to this paper, they do not explicitly incorporate the risk preferences of either poilcymakers or investors into their respective decision-making problems. Consequently, this paper provides a number of important contributions for policymakers when considering the most appropriate Feed-in Tariff choice:

1. The policymaker's preferences are less dominant than those of investors when degrees of risk aversion are of a similar magnitude.

2. Market price risk should be shared except under circumstances of extreme investor/consumer indifference to risk.

3. Shared upside policies offer very similar levels of utility to cap \& floor policies (see Section 3.2 for a detailed description of the FiTs considered in this work). However, when policymakers are extremely risk averse and investors are modestly risk averse, the expected cost of the cap \& floor policy is slightly smaller.

4. When policymakers are risk averse and investors have low levels of risk aversion, constant premium policies offer higher utility when compared shared upside policies. However, in Expected Money Value (EMV) terms, constant premium policies are always more expensive. 
The efficient division of risk is also common in other contexts. For instance, Raviv (1979) show that an optimal insurance contract may be designed by first identifying the insured's optimal level of coverage as a function of the insurance premium and then identifying the optimal premium from the insurer's perspective. Mahul (2001) apply a similar framework to identify how weatherdependent production may insure against climate risks, whilst Ma and McGuire (1997) model the design of optimal health insurance contracts. The following section presents a tool with which policymakers can identify the optimal point in this trade-off when choosing a suitable FiT policy structure.

\section{Methodology}

The methodology of this paper consists of three steps. First, we model electricity market prices. Second, we specify efficient FiT specifications which allow for investor remuneration/policy cost to be identified. Third, these cost/remuneration calculations are used alongside a model of risk averse investment to determine an optimal FiT design conditional on risk preferences. These steps will be outlined in turn in this section. FiTs transfer risk from investors, through policymakers, to consumers. To aid the discussion that follows, we refer to policymaker burden alone. However, this may be interpreted as a collective term for the total burden incurred by all consumers. Tables 1 - 4 display the indices, parameters, functions and decision variables of the overall model respectively.

Table 1: Model indices

\begin{tabular}{|l|l|}
\hline Monte-Carlo simulation scenarios & $l$ \\
Timesteps & $t$ \\
\hline
\end{tabular}

\subsection{Market Prices}

The market price received by the renewable investor varies by jurisdiction. For the purpose of this analysis, we choose an Irish case study and thus consider annual Volume Weighted Average Prices (VWAP) (Farrell et al., 2017). This is the annual average electricity price weighted by the volume of electricity generated through renewable sources and is used in certain jurisdictions such as Ireland to calculate wind remuneration (Doherty and O'Malley, 2011; Farrell et al., 2017).

Fleten et al. (2007) have comprehensively reviewed methodologies to model electricity prices in the analysis of renewable energy investment (Pindyck, 1999; Pinkdyck, 2001; Schwartz and Smith, 2000) finding Geometric Brownian Motion (GBM) appropriate. This is because renewable energy investment is a long-term investment and thus long term price trends are of importance, even when analysing investments in markets with electricity prices of hourly, daily or monthly fluctuations. Thus, results are of negligible sensitivity to intra-annual variability (Pindyck, 1999; 
Table 2: Model parameters with baseline values

\begin{tabular}{|c|c|}
\hline Parameter & Value \\
\hline Capital Cost $(A)$ & $€ 1.76 \mathrm{~m} / \mathrm{MW}^{a}$ \\
\hline Annual Operations \& Maintenance Cost $(O)$ & $2 \%$ of capital cost ${ }^{a}$ \\
\hline Irish Single Electricity Market (SEM) Installation target $\left(Q^{\text {TARGET}}\right)$ & $4,630 \mathrm{MW}^{b}$ \\
\hline Capacity Factor $(u)$ & $0.35^{a}$ \\
\hline Availability $(v)$ & $0.95^{a}$ \\
\hline Maximum $Q\left(Q^{\max }\right)$ & $16 \mathrm{GW}^{c}$ \\
\hline Long-run electricity Price Growth $(\bar{\mu})$ & $0.0155^{a}$ \\
\hline Rate of change parameter for generation function $(\gamma)$ & $\left(6.75 \times 10^{-5}\right)^{b}$ \\
\hline Market price parameter $(\eta)$ & $0.01^{e}$ \\
\hline Market price parameter $(\kappa)$ & $0.001^{d}$ \\
\hline Electricity Price Volatility $(\sigma)$ & $0.13^{a}$ \\
\hline Initial VWAP $\left(S_{0}\right)$ & $52.41(€ / \mathrm{MW} \mathrm{h})^{a}$ \\
\hline Discount Rate (r) & 0.06 \\
\hline Investors' pre-existing wealth $\left(w_{\mathrm{pre}}^{\mathrm{Inv}}\right)$ & $€ 18.98 \mathrm{bn}{ }^{e}$ \\
\hline Policymaker's pre-existing wealth ( $\left.w_{\mathrm{pre}}^{\text {policy }}\right)$ & $€ 38.36 \mathrm{bn}^{e}$ \\
\hline Investors' level or risk aversion $(\alpha)$ & $0-4$ \\
\hline Policymaker's level or risk aversion $(\beta)$ & $0-4$ \\
\hline Total number of simulations $(L)$ & 100,000 \\
\hline Probability associated with each scenario $l\left(P R_{l}\right)$ & $\frac{1}{100,000}$ \\
\hline Total number of yearly timesteps $(T)$ & 20 \\
\hline
\end{tabular}

Source: ${ }^{a}$ calibrated to Doherty and O'Malley (2011); ${ }^{b}$ callibrated to Mc Garrigle et al. (2013);

${ }^{c}$ SEAI (2011); ${ }^{d}$ calibrated to IWEA (2011); ${ }^{e}$ own calculation.

Pinkdyck, 2001; Schwartz and Smith, 2000). Given this finding, GBM has been employed in many circumstances for the modelling of long-term electricity price processes of annual timesteps (e.g. Wickart and Madlener, 2007; Yang and Blyth, 2007; Heydari et al., 2012; Siddiqui and Maribu, 2009; Siddiqui and Fleten, 2010; Zhu, 2012). Following this convention, along with modelling in the context of an annual timestep for which GBM is considered appropriate (see Farrell et al. (2017) for further discussion of this), GBM is chosen to model annual electricity prices in this paper.

The market price for scenario $l$ and timestep $t$ is represented by $S_{l, t}$. Values for this parameter are generated through Monte-Carlo simulations via the following stochastic differential equation for GBM:

$$
d S=\mu(Q) S d t+\sigma S d \omega,
$$


Table 3: Model functions

\begin{tabular}{|l|r|}
\hline Feed-in Tariff price for timestep $t$ and scenario $l(€ / \mathrm{MW} \mathrm{h})$ & $P_{l, t}$ \\
System price for timestep $t$ and scenario $l(€ / \mathrm{MW} \mathrm{h})$ & $S_{l, t}$ \\
System price average growth rate $(\%)$ & $\mu$ \\
Policymaker cost for timestep $t$ and scenario $l(€ / \mathrm{MW} \mathrm{h})$ & $F_{l, t}$ \\
Total policymaker cost for and scenario $l(€)$ & $F_{l}$ \\
Policymaker utility for scenario $l$ & $U_{l}^{\text {policy }}$ \\
Polciymaker wealth for scenario $l(€)$ & $W_{l}^{\text {policy }}$ \\
Investor utility for scenario $l$ & $U_{l}^{\text {Inv }}$ \\
Investor wealth for scenario $l(€)$ & $W_{l}^{\text {Inv }}$ \\
Investor profit for scenario $l(€)$ & $\Pi_{l}^{\text {Inv }}$ \\
Total investor costs $(€)$ & $C$ \\
Total investor generation $(\mathrm{MW} \mathrm{h)}$ & $G$ \\
\hline
\end{tabular}

Table 4: Model varaibles

\begin{tabular}{|l|r|}
\hline Policymaker decision variables & \\
\hline Feed-in Tariff price premimum (€/MW h) & $X$ \\
Feed-in Tariff price floor (€/MW h) & $K$ \\
Feed-in Tariff proportion of market upside (€/MW h) & $\theta$ \\
Feed-in Tariff price cap (€/MW h) & $\bar{S}$ \\
\hline \hline Investor decision variables & $Q$ \\
\hline Installed capacity of renewable energy ${ }^{a}(\mathrm{MW})$ & \\
\hline \multicolumn{2}{|l|}{ While $Q$ is a variable of the investors' problem, the overall } \\
optimisation problem is solved such that $Q$ must equal $Q^{\text {TARGET }}$.
\end{tabular}

where

$$
\mu(Q)=\bar{\mu}+\eta e^{-\kappa Q}
$$

The main parameters of this process are $\mu$, which is the drift or average trend of growth, and $\sigma$ which is the volatility around the average trend. Following Farrell et al. (2017), Equations (1) and (2) show that changes in the $Q$ of renewables installed affect the rate of growth $(\mu)$ in VWAP. In this way, any changes in prices due to the level of deployment are endogenous to the assumed price process and thus the investment decision. VWAPs are modelled this way because the 'merit order effect' of certain renewables with no marginal cost (e.g. wind, wave solar; Sensfuß et al., 2008) will result in lower rates of market price growth as the quantity $Q$ of installed capacity increases.

The parameter $\bar{\mu}$ represents the rate of growth when a $Q^{\max }$ level of installation is in place, 
thus including all merit order effects while $\eta e^{-\kappa Q}$ models the pattern with which the rate of growth changes with each additional $\mathrm{Q}$ capacity addition. Both $\eta$ and $\kappa$ are model parameters, where $\bar{\mu}+\eta$ represents the rate of growth when $Q$ is zero, while $\kappa$ determines the elasticity of the rate of growth with respect to $Q$. These parameters are chosen such that merit order effects impact the rate of growth in a pattern that is consistent with expectations. Increments of the Wiener process are represented by $d \omega$ (Hull, 2003). In Section 5, equation (1) is used to generate $L=100,000$ Monte-Carlo simulation scenarios.

VWAP is the only stochastic measure considered in this paper. However, Nahmmacher et al. (2014), Wogrin et al. (2016), and Wogrin and Gayme (2015) all note that ignoring the temporal and spatial variability of renewable energy output with regard to demand, in long-term models, may lead to upwardly biased estimates of renewable energy adoption. The correlation of output with demand is of importance if it affects the level of remuneration or if operation is determined by this chronology. However, this effect is negligible in this work as VWAP, and hence renewable output, are calculated on a yearly basis. Any influence this correlation has on market prices is captured by the stochastic market price process. This is in contrast to other applications, as outlined by Nahmmacher et al. (2014), which require an understanding of the short-term chronology and correlations.

\subsection{Feed-in Tariff Prices}

Once market prices are specified, we must specify efficient feed-in tariff prices. Illustrated in Figure 1, we consider three different FiT designs that transfer market price risk in different ways:

1. Constant Premium: investors receive a constant premium price in addition to the full market price. Thus, investors are fully exposed to market price risk. This tariff is also known as a Feed-in Premium.

2. Shared Upside: investors receive a guaranteed price floor with market upside shared between investors and the policymaker. Hence, market price risk is shared between investors and the policymaker.

3. Cap \& Floor: investors receive the full share of market price. However, lower and upper bounds are placed on the price received. Consequently, market price risk is again shared between investors and the policymaker.

Assuming both players are risk neutral, Farrell et al. (2017) show how each of these FiTs may be efficiently specified using option pricing theory. For the shared upside policy, this specification results in an inverse relationship between the efficient price floor and the degree of market 'upside' offered to investors. When a greater share of market upside is offered to investors, the efficient price floor falls to take into account of the value of the market upside and hence a greater proportion of market price risk is transferred from the policymaker to the investors. A similar relationship was 
found between the efficient upper and lower bounds for the cap \& floor policy with the efficient price floor falling as the efficient price cap increases.

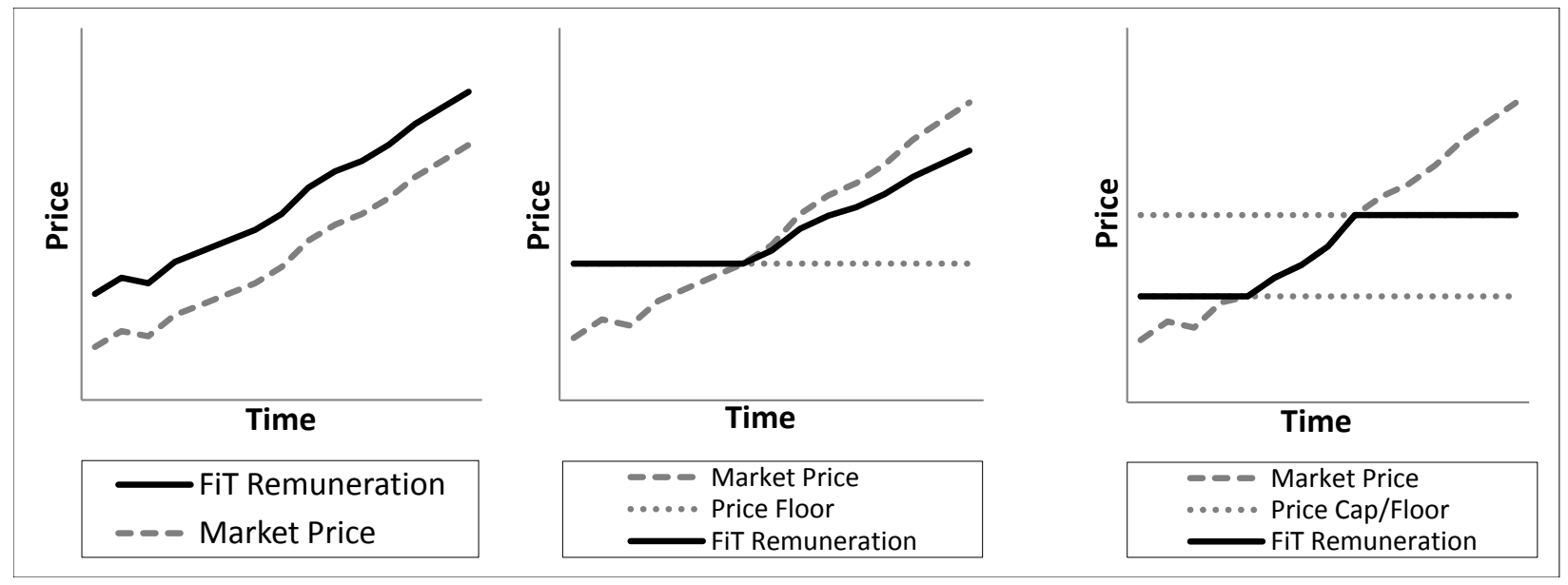

Figure 1: Payment structures: (left) constant premium, (middle) shared upside, (right) cap \& floor.

\subsubsection{Constant Premium}

For a constant premium (CP) tariff, the discounted price received by the investor during time $t$ under scenario $l\left(P_{l, t}^{\mathrm{CP}}\right)$ is the discounted value of the premium, $X$, added to the discounted value of market remuneration $\left(S_{l, t}\right)$ :

$$
P_{l, t}^{\mathrm{CP}}=e^{-r t}\left(X+S_{l, t}\right)
$$

where $r$ is the discount rate. The cost for the policymaker, at time $t$, is constant at

$$
F_{l, t}^{\mathrm{CP}}=e^{-r t} X
$$

\subsubsection{Shared Upside}

The value of remuneration under a shared upside (SU) policy comprises two constituent elements; a minimum price guarantee and a portion of market upside. This FiT structure resembles a European call option, where the investor has the right, but not the obligation to buy at time $t$ at a given price (i.e., price floor $K$ ). The share of market upside received by the investor is denoted by $\theta$. The discounted price of $P_{l, t}^{\mathrm{SU}}$ under a shared upside policy at time $t$ under scenario $l$ is:

$$
P_{l, t}^{\mathrm{SU}}=e^{-r t}\left(K+\theta\left(\max \left(S_{l, t}-K, 0\right)\right)\right)
$$

while the discounted policy cost under a shared upside regime is

$$
F_{l, t}^{\mathrm{SU}}=e^{-r t}\left(\max \left(0, K-S_{l, t}\right)-(1-\theta) \max \left(0, S_{l, t}-K\right)\right) .
$$




\subsubsection{Cap \& Floor}

A cap \& floor (CF) policy is also like a call option, where investors have the right to buy at a price floor $(K)$. However, should the price exceed the cap $(\bar{S})$, remuneration is equal to the cap and no more. The price $P_{l, t}^{\mathrm{CF}}$ under this policy design is:

$$
\left.P_{l, t}^{\mathrm{CF}}=e^{-r t}\left(K+\max \left(S_{l, t}-K\right), 0\right)-\max \left(S_{l, t}-\bar{S}, 0\right)\right)
$$

the discounted cost of the FiT at time $t$ is

$$
F_{l, t}^{\mathrm{CF}}=e^{-r t}\left(\max \left(0, K-S_{l, t}\right)-\max \left(0, S_{l, t}-\bar{S}\right)\right)
$$

\subsection{Optimisation model formulation}

The procedure of modelling renewable energy investment is a Stackelberg leader game. Industry investors decide on a $Q$ level of investment in a given renewable energy technology, conditional on the FiT price offered by the policymaker. In this Stackelberg game, the leader (policymaker) chooses their strategy (FiT price) first with followers (investors) implementing their strategy (investment) conditional on the leader's choice (Chang et al., 2013; Fudenberg and Tirole, 1991). Under this framework investors are modelled as a whole and hence as a single player. The policymaker anticipates the investors' strategic response and chooses the FiT price that results in deployment of the desired quantity of renewable generation. This means that the investors' optimisation problem is embedded in the policymaker's optimisation problem.

It is assumed that a policymaker wishes to incentivise the deployment of $Q^{\text {TARGET }}$ units, a target which is set exogenously. Other works, such as Siddiqui et al. (2016) assume that when modelling investment in renewable energy capcity, the capacity target is a decision variable of the model. However, setting $Q^{\text {TARGET }}$ exogenous to the model in this work is motivated by the European Union's binding energy targets where each member state must increase the proportion of electricity they generate from renewable sources before 2020. In the Republic of Ireland, this target is set at 40\% (DCCAE, 2009). Mc Garrigle et al. (2013) estimate that this target will require the installation of $4630 \mathrm{MW}$ of renewable energy capacity and this is the level that $Q^{\text {TARGET }}$ is set at in this paper.

The bi-level game modelled in this work operates over $T$ discrete time periods in a time horizon $[1, \mathrm{~T}]$, indexed by $t$. It builds on the model developed in Farrell et al. (2017), however, the present work incorporates the risk preferences of the two different types of players into their objective functions which provides a more realistic modelling framework. As explained previously, both the policymaker and investors are assumed to be risk neutral in Farrell et al. (2017).

FiTs vary according to the degree of certain and uncertain payments in overall remuneration. For investors, a greater proportion of certain payments in overall remuneration reduces market 
price risk. This is achieved by offering the investor a higher price floor and thus a lower proportion of market upside/lower cap. However, offering a policy of greater revenue certainty for investors requires a greater degree of market price uncertainty to be borne by the policymaker, as a higher floor exposes the policymaker to a greater cost should market prices be low. A FiT must be chosen such that the balance of uncertain and certain remuneration incentivises investors to install $Q^{\text {TARGET }}$ units whilst allowing policymakers to minimise the welfare loss associated with policy cost and exposure to market price risk.

There are many methods with which one may model this trade-off between expected cost or remuneration and exposure to risk, including Conditional Value at Risk (CVaR)-based methodologies, mean-variance functional forms and utility functions such as Constant Absolute Risk Aversion (CARA) and Constant Relative Risk Aversion (CRRA). Effective modelling captures observed patterns of risk aversion. As Chiu and Wong (2013) discuss, optimal investment decisions are commonly evaluated based on maximizing the expected utility of future wealth (Chiu and Wong, 2013; Fan et al., 2010, 2012; von Neumann and Morgenstern, 1947). Furthermore, research suggests that consumers are more averse to FiT costs as they comprise a greater share of total electricity cost (Batlle, 2011; Leepa and Unfried, 2013; Loreck et al., 2012) and thus policymakers may become more averse to FiT cost uncertainties as they comprise a greater proportion of electricity cost. Taking this into account, a functional form that incorporates cost as a function of wealth and/or total electricity expenditure may be most appropriate to model policymaker aversion to market price risk.

Given the outlined requirements, a concave utility function may be most appropriate in capturing the required relationship. The higher the curvature of a concave utility function, the higher the aversion to risk. Concave utility functions with high levels of curvature give relatively lower utility on high values of wealth and thus model risk averse behaviour. The Constant Relative Risk Aversion (CRRA) utility function captures this relationship for both investor and policymaker utility; see equations (9) and (17) respectively. While a Constant Absolute Risk Aversion (CARA) utility function has a constant degree of risk aversion regardless of the level of the outcome variable being analysed (e.g. wealth, consumption, cost), a CRRA utility function has a scaling factor ( $w_{\text {pre }}^{\text {Inv }}$ and $w_{\text {pre }}^{\text {policy }}$ in equations (10) and (18) respectively) which calibrates the agent's degree of risk aversion (Arrow, 1971; Meyer and Meyer, 2005). This allows for the risk aversion as a function of wealth to be calculated, an outlined requirement for effective calibration in the context of policymaker risk aversion.

An added benefit of the CRRA framework is transparency with respect to calibration; A CRRA utility function provides the ability to interpret utility values as a 'certainty equivalent', allowing for calibration to observed levels of risk aversion. Sensitivity to altering the degree of risk aversion is also easily identified and intuitively presented (see Section 3.5). Given the precedent of usage, 
outlined suitability and transparency of calibration, a CRRA functional form is chosen to model policymaker risk aversion.

Much of the literature to date has employed a CRRA functional form when analysing investment in energy markets and large scale investments (Attema et al., 2010; Amde-Manesme et al., 2015; Chronopoulos et al., 2014; Chunxiang et al., 2016; Cotter and Hanly, 2012; Chiu and Wong, 2013; Wakker, 2008). In an analysis of investment in the energy sector, Willems and Morbee (2010) found that a correctly calibrated CRRA functional form had similar findings to alternate specifications. Given this precedent of use and also the flexibility of the CRRA function to consider varying degrees of risk aversion, this functional form is also employed to model investor risk aversion.

\subsubsection{Investors' problem (lower-level)}

Under a CRRA utility function, utility for the investor and policymaker is comprised of a scaling parameter and profit/cost of deployment. Generally, pre-existing wealth is used for this scaling parameter. To ensure that our results are calibrated to realistic degree of risk aversion, we choose the scaling parameter such that it corresponds to both levels of wealth and resulting rates of risk aversion that are deemed reasonable given the literature. Such flexibility further highlights the benefit of the CRRA utility function over less flexible forms such as the CARA functional form and CVaR.

We model investors in a given market together as one entity. Following Baron (1970) we assume that the aggregated utility function is the summation of the individual utility functions for each generator. In order to facilitate analysis of the effects of risk aversion on investment decisions, it must be assumed that all firms in the industry have the same utility function and the same probability assessments Baron (1970) ${ }^{1}$.

The investors' utility, under scenario $l$, is modelled using a CRRA utility function of wealth:

$$
U_{l}^{\mathrm{Inv}}\left(W_{l}^{\mathrm{Inv}}\right)= \begin{cases}\left(\frac{1}{1-\alpha}\right)\left(W_{l}^{\mathrm{Inv}}\right)^{1-\alpha} & \text { if } \alpha \neq 1 \\ \ln \left(W_{l}^{\mathrm{Inv}}\right) & \text { if } \alpha=1\end{cases}
$$

where the investors' wealth under scenario $l$ is

$$
W_{l}^{\mathrm{Inv}}=w_{\mathrm{pre}}^{\mathrm{Inv}}+\Pi_{l}(Q)
$$

\footnotetext{
${ }^{1}$ The size and type of investing firms may affect risk appetite (GCF, 2014), however empirical research has found that this effect may be small and statistically insignificant amongst larger firms (Sadorsky, 2012), which comprise the majority of wind investors in markets such as Ireland. A heterogeneous risk profile may be required for technologies (e.g. solar, biomass) or markets with a great proportion of small investors and is a potential future extension.
} 
which is comprised of the pre-existing wealth $w_{\text {pre }}^{\text {Inv }}$ and profit from investment, $\Pi_{l}(Q)$. The parameter $\alpha$ is the curvature of the investors' utility function and hence represents how risk averse they are. The higher the level of $\alpha$ the higher the aversion to risk. When $\alpha=0$ the investors' utility equals their wealth and hence they are assumed risk neutral. The investors' profit and hence utility is uncertain and subject to fluctuations in market prices and thus varies from scenario to scenario. The amount of uncertainty differs depending on the policy enacted. The investors' profit is also dependent on $Q$, the number of installed units of renewable energy technology. Total industry profit $\Pi_{l}(Q)$ for scenario $l$ is defined as follows

$$
\Pi_{l}(Q)=\sum_{t=1}^{T}\left[P_{l, t}(Q) G(Q)\right]-C(Q)
$$

where $P_{l, t}$ takes one of the different forms described in Section 3.2 (i.e., equations (3), (5) or (7) ) depending on the FiT being considered.

For the installation of $Q$ units, $C(Q)$ is the sum of industry-level capital $(A)$ and operating $(O)$ costs (including any required return to personnel, capital, etc.), discounted according to a discount rate $r$ :

$$
C(Q)=A Q+\sum_{t=1}^{T} e^{-r t} O Q
$$

The total amount electricity generated from renewable sources is modelled in a similar way to (Farrell et al., 2017) using the following equations:

$$
G(Q)=B(Q) u v h
$$

where

$$
B(Q)=Q^{\max }\left(1-e^{-\gamma Q}\right)
$$

The parameter $Q^{\max }$ is the maximum potential $Q$ while $\gamma$ is a parameter controlling the rate of change. The function $B(Q)$ reflects the nameplate capacity or maximum effect of investors. It models how the rate of increase for renewable energy generation slows as the installed capacity increases, i.e., $\frac{\partial B}{\partial Q}=Q^{\max } \gamma e^{-\gamma Q}$ is a strictly decreasing function. Consequently, for nonsynchronous generation such as wind, solar and wave, this functionality captures how increased curtailment follows from increased levels of installation. Other issues such as poorer site and resource availability are also captured. As $B(Q)$ is an hourly value, it is multiplied by the total number of hours in each time period $(h)$, the operational availability net of maintenance and other such outages $(v)$ and the capacity factor for initial units $(u)$. Hence, $G(Q)$ represents the total amount of electricity generated from renewable sources during time $t$. 
The capacity factor is the average power generated, divided by the rated peak power ${ }^{2}$. A higher (lower) capacity factor would lead to a higher (lower) level of remuneration and a lower (higher) FiT price. Similarly, a higher (lower) capacity factor would lead to a higher (lower) rate of output per MW installed and thus a lower (higher) MW target.

The investors' problem, which is the lower-level problem in the overall optimisation, is to maximise expected utility by choosing a level of installed capacity. Their objective function is

$$
\max _{Q} U^{\mathrm{Inv}}=\max _{Q} \sum_{l=1}^{L} P R_{l} U_{l}^{\mathrm{Inv}}
$$

where $P R_{l}$ is the probability associated with scenario $l$. The investors' decision variable is $Q$ (level of installed capacity). Their problem is unconstrained ${ }^{3}$ and, assuming concavity, the investors' utility function is maximised when

$$
\frac{\partial U^{\mathrm{Inv}}}{\partial Q}=0
$$

\subsubsection{Policymaker problem (upper-level)}

In a similar manner to above, the policymaker's utility, under scenario $l$, is modelled using a CRRA utility function of wealth:

$$
U_{l}^{\text {policy }}\left(W_{l}^{\text {policy }}\right)= \begin{cases}\left(\frac{1}{1-\beta}\right)\left(W_{l}^{\text {policy }}\right)^{1-\beta} & \text { if } \beta \neq 1 \\ \ln \left(W_{l}^{\text {policy }}\right) & \text { if } \beta=1\end{cases}
$$

where

$$
W_{l}^{\text {policy }}=w_{\text {pre }}^{\text {policy }}-F_{l}(Q),
$$

represents the policymaker's wealth for scenario $l$. This wealth is comprised of pre-existing wealth, $w_{\text {pre }}^{\text {policy }}$, less the cost of the FiT design being considered. The parameter $\beta$ is the curvature of the policymaker's utility function and hence represents how risk averse they are. When $\beta=0$ the policymaker's utility equals their wealth and hence they are assumed risk neutral.

As with the investors' profits, the $\operatorname{cost} F_{l}(Q)$ is subject to fluctuations in market prices and thus varies from scenario to scenario whilst also depending on the amount of units of renewable energy

\footnotetext{
${ }^{2}$ The chosen capacity factor is sourced from Doherty and O'Malley (2011) as the expected capacity factor for Ireland over a long-term horizon. While there may be some difference between a capacity factor for multiple and single years, this corresponds roughly to the average value for the 2020 capacity factor duration curve reported by Mc Garrigle et al. (2013) for onshore wind.

${ }^{3}$ While this suggests that the optimal value for the variable $Q$ may be negative, in practise, constraint (21) in the overall optimisation problem ensures that the policymaker chooses the FiTs that ensure the optimal value for $Q$, that the investors choose, is equal to $Q^{\mathrm{TARGET}}$.
} 
technology installed. This cost is the sum of the difference between the price that the investors receives $P_{l, t}$ and the market price $S_{l, t}$ :

$$
F_{l}(Q)=\sum_{t=1}^{T} F_{l, t} G(Q)=\sum_{t=1}^{T}\left(P_{l, t}-S_{l, t}\right) G(Q)
$$

where $F_{i, t}$ takes one of the different forms described in Section 3.2 (i.e., equations (4), (6) or (8)) $)^{4}$ depending on the FiT being considered.

The policymaker's problem is to choose the FiT that maximises their expected utility whilst ensuring that the investors' expected utility is maximised by choosing $Q^{\text {TARGET }}$ units of renewable energy technology. The policymaker's problem is

$$
\max U^{\text {policy }}=\max \sum_{l=1}^{L} P R_{l} U_{l}^{\text {policy }}
$$

subject to

$$
\begin{gathered}
Q=Q^{\text {TARGET }}, \\
\frac{\partial U^{\mathrm{Inv}}}{\partial Q}=0 .
\end{gathered}
$$

The policymaker's decision variables are the varaibles associated with the three different FiT policies described in Section 3.2. To obtain the optimal values for these variables, the model is solved three times; once considering each of the different FiTs separately. The policymaker's decision variable is $X$ when the constant premium policy is being considered, i.e., when the FiT and its associated costs are being determined by equations (3) and (4) respectively. When the shared upside policy is being considered their decision variables are $K$ and $\theta$ as the FiT and its associated costs are determined by equations (5) and (6). When the cap \& floor policy is being considered, their decision variables are $K$ and $\bar{S}$ as the FiT and its associated costs are determined by equation (7) and (8).

The overall optimisation problem for the Stackelberg game is defined by equations (20) - (22). Equation (22) embeds the investors' optimality condition, and hence their optimisation problem, as a constraint in the policymaker's problem. Along with constraint (21), it ensures that the policymaker chooses the FiT levels that allows investors to maximise their expected utility with $Q^{\text {TARGET }}$ units installed. Embedding the investor's optimality condition as a constraint in the policymaker's problem ensures that the overall model is a single-level Mathematical Program with Equilibrium Constraints (MPEC) (Gabriel et al., 2012).

\footnotetext{
${ }^{4}$ As described in Section 3.2, both $P_{l, t}$ and $S_{l, t}$ depend on $Q$.
} 
If the policymaker's problem did not include constraint (22) then they would have greater freedom when choosing optimal FiT levels as this is the only constraint that depends on the FiT levels. In this case, policymaker's utility is maximised by choosing $X=K=\theta=\bar{S}=0$. If the optimal FiT attributes were chosen this way, then the investors would not receive enough remuneration for it to be optimal for them to invest in $Q^{\text {TARGET }} \mathrm{MW}$ of renewable energy (assuming the baseline parameters of Section 4). Thus, the overall problem would become infeasible as constraint (21) would be unable to be satisfied. Similarly, if the investors problem was solved as an independent single-level problem where the investors only received the market price and not any FiT, then they would again not receive enough remuneration for it to be optimal for them to install $Q^{\text {TARGET }} \mathrm{MW}$ of renewable energy.

The policymaker's problem is set up as a maximisation problem to aid computation. As preexisting electricity cost is held constant, it is equivalent to minimising the FiT cost. The CRRA specification allows aversion to FiT cost to be considered relative to total electricity cost.

\subsection{Solving the problem}

The model is solved using the numerical computing software MATLAB ${ }^{5}$. In the numerical examples presented in Section 5 the derivative in equation (22) is approximated using finite differences as follows:

$$
\frac{\partial U^{\mathrm{Inv}}}{\partial Q} \approx \frac{U^{\mathrm{Inv}}(Q)-U^{\mathrm{Inv}}(Q-\Delta Q)}{\Delta Q}=0,
$$

where $\Delta Q$ is small. In order to satisfy constraint (21), equation (23) is always evaluated at $Q=$ $Q^{\text {TARGET }}$. For each FiT policy considered, the market price scenarios $\left(S_{l, t}\right)$ are simulated using Monte-Carlo simulation via equation (1). Thus, both policymaker and investor wealth, and hence the expected utilities in equations (20) and (23), are also calculated via Monte-Carlo simulation.

For the constant premium policy, the optimal value for $X$ is obtained by solving equation (23) for $X$. For the shared upside policy, equation (23) is solved for $K$ assuming $\theta$ is fixed. This is done is 101 times; once for each value of $\theta$ in the set $\{0,0.01,0.02, . ., 1\}$. For each value of $\theta$ a corresponding value of $K$ is obtained from equation (23). The $(K, \theta)$ pair that maximises policymaker utility is chosen as optimal. For the cap \& floor policy, equation (23) is solved for $\bar{S}$ assuming $K$ is fixed. This is done for each value of $K$ in the set $\phi=\left\{K_{\theta=1}, K_{\theta=1}+0.01, K_{\theta=1}+\right.$ $\left.0.02, . ., K_{\theta=0}\right\}$, where $K_{\theta=1}$ and $K_{\theta=0}$ are the values for $K$ obtained when equation (23) is solved with $\theta$ fixed at $\theta=1$ and $\theta=0$, respectively. Having $\theta=1$ in the shared upside policy is the same as having $\bar{S}=\infty$ in the cap \& floor policy. Hence, $K_{\theta=1}$ is the $K$ associated with the largest possible value for $\bar{S}$. Similarly, having $\theta=0$ in the shared upside policy is the same as having $\bar{S}=K$ in the cap \& floor policy. Therefore, $K_{\theta=0}$ is the $K$ associated with the smallest possible

\footnotetext{
${ }^{5}$ https://uk.mathworks.com/products/matlab/
} 
value for $\bar{S}$. Consequently, the set $\phi$ represents each possible value for $K$ (to the nearest cent) under the cap \& floor policy. For each of these values, a corresponding value of $\bar{S}$ is obtained from equation (23) and, as above, the $(K, \bar{S})$ pair that maximises policymaker utility is chosen as optimal. Each time equation (23) is solved for a model variable, MATLAB's f solve function is utilized.

For the results described in Section 5, the Central Processing Unit (CPU) time required to solve the problem, for all $\alpha$ and $\beta$ combinations in total, for the constant premium, shared upside and cap \& floor policies is approximately $118,8,698$ and 44,373 seconds respectively. These figures were obtained using a $3.3 \mathrm{GHz}$ i5-4590 quad-core processor with $8 \mathrm{~GB}$ of RAM.

\subsection{Interpreting utility}

Utility measures the risk-adjusted welfare value of expected cash amounts. For this work, the derived utility values for the investors and the policymaker are obtained using equations (9) and (17) respectively. Certainty Equivalent (CE) is the certain amount of remuneration/policy cost that yields the same utility as an uncertain alternative (Hardaker et al., 2004) and is calculated as the inverse of the derived utility value. The investors' $\mathrm{CE}$ is

$$
C E^{\mathrm{Inv}}= \begin{cases}(1-\alpha)\left(U^{\mathrm{Inv}}\right)^{\frac{1}{1-\alpha}}-w_{\mathrm{pre}}^{\mathrm{Inv}} & \text { if } \alpha \neq 1, \\ e^{U^{\mathrm{Inv}}}-w_{\mathrm{pre}}^{\mathrm{Inv}} & \text { if } \alpha=1\end{cases}
$$

while the policymaker's CE is

$$
C E^{\text {policy }}= \begin{cases}(1-\beta)\left(U^{\mathrm{Inv}}\right)^{\frac{1}{1-\beta}}-w_{\mathrm{pre}}^{\text {policy }} & \text { if } \beta \neq 1, \\ e^{U^{\mathrm{Inv}}}-w_{\mathrm{pre}}^{\text {policy }} & \text { if } \beta=1\end{cases}
$$

When $\alpha=0$ and $\beta=0, \mathrm{CE}$ is equivalent to investors' expected profit and policymaker's expected cost respectively. The expected value of uncertain remuneration may be higher than its CE, reflecting aversion to risk (Hardaker et al., 2004; Pratt, 1964). In this way, the CE of a return falls as remuneration becomes more uncertain. Similarly, the CE of a cost increases with uncertainty.

\section{Data}

In this section, the data for the analysis is presented. While the analysis may be carried out for any renewable technology and profile of risk aversion, wind turbine deployment in Ireland is chosen for this work. A stylised case study following Farrell et al. (2017) is considered, with parameters outlined in Table 2. Ireland has a renewable energy penetration target of 40\% by 2020. Mc Garrigle et al. (2013) state that this corresponds to 4630MW under a scenario of $75 \%$ system 
non-sychronous penetration and a low level of offshore wind. We therefore chose 4630MW as our $Q^{\text {TARGET }}$ parameter. We assume that the cost parameters of Table 2 include any ordinary profits and additional remuneration required to cover non-market price-related risks. This allows us to focus on any additional remuneration required to compensate for additional exposure to uncertain market prices due to FiT design.

It is assumed that all investment occurs at first time period ${ }^{6}$. It is also assumed that a wind turbine is operational for $T=20$ years, with FiT remuneration available during all 20 years of operation. In reality, there is a possibility that FiT policies may be terminated retroactively before expiry of the 20-year period. However, Boomsma and Linnerud (2015) and Del Rio and MirArtigues (2012) highlight that this undermines the effectiveness of a FiT regime and should be avoided. The literature therefore recommends that for a FiT to be effective this commitment must be binding for the entire duration.

The discount rate represents the risk-free rate of return and is calibrated to rates commonly employed in Irish case studies (Farrell et al., 2017; Doherty and O’Malley, 2011). Market price parameters $\eta$ and $\kappa$ are chosen such that the difference in the market prices in 2020, when no wind is in place and when $4630 \mathrm{MW}$ of wind capacity $\left(Q^{\text {TARGET }}\right)$ is in place, is the same difference as that observed by IWEA (2011) for a comparable level of wind deployment. The rates of market price growth and volatility are calibrated to correspond to simulations carried out by Doherty and O’Malley (2011) who used a Generalised Extreme Value (GEV) distribution to simulate market price distributions. Doherty and O'Malley (2011) used an implied rate of volatility for a 20-year time period and hence the volatility rate used in this paper is also implied. We follow the precedent in the majority of the literature and use Geometric Brownian Motion (see Section 3.1). The GEV distribution simulates a greater prevalence of upside volatility, resulting in a greater number of high market prices, compared to the GBM approach taken in this paper. Therefore, simulations carried out using the GBM approach are likely to yield lower expected market returns and therefore require slightly higher efficient FiT prices than if a GEV distribution were employed.

As outlined in Section 3.2, the policymaker's wealth ( $\left.W_{l}^{\text {policy }}\right)$ is calculated as the policymaker's pre-existing wealth, $w_{\text {pre }}^{\text {policy }}$, less the cost of the FiT policy, $F_{l}(Q)$. The parameter $w_{\text {pre }}^{\text {policy }}$ is chosen such that it represents the discounted value of electricity generated during 20-year time horizon (SEMO, 2015).

To further ensure that this represents a realistic parameter, the observed degrees of risk aversion are compared to those expected by the literature. Hirst (2002) estimate that removing consumers' exposure to wholesale market price risk by providing a fixed electricity price adds $5-10 \%$ onto

\footnotetext{
${ }^{6}$ The dynamics of investment within a investment window is outside the scope of this paper and therefore investment in a single time period is assumed for tractability. Please see Boomsma and Linnerud (2015) for a discussion of this.
} 
electricity cost. Zhang and Wang (2009) analyse a number of such contracts, and find that contract prices may range anywhere from $0.38 \%$ to $23 \%$ of the electricity price, depending on the portion of uncertainty removed. For fixed price tariffs with a high fixed price, they find that hedge contracts may range from $0.38-4.12 \%$. This literature focuses on limiting exposure to all market price risk, not just the FiT cost portion. Given that FiT costs comprise a smaller proportion of electricity cost than the total electricity cost that is analysed in these papers, we take this lower range as being a more representative range of hedge values considered. Calibrating our model to this level of risk aversion requires a $w_{\text {pre }}^{\text {policy }}$ parameter of $€ 38.36 \mathrm{bn}$, which corresponds to expected value of electricity throughout the investment period and also approximates the total discounted value of electricity generated in the Irish Single Electricity Market ${ }^{7}$. We thus choose $€ 38.36 \mathrm{bn}$ for our baseline analysis but test senstivity to alternate ranges in Section 5.3.1.

Similarly, the investors' pre-existing wealth $\left(w_{\text {pre }}^{\text {Inv }}\right)$ is chosen such that investors' risk aversion is of a range considered realistic. As above, we calibrate this to a level of wealth for a representative investor, with further checks to ensure that the level of modelled risk aversion is within reasonable bounds. The majority of wind installations in Ireland are carried out by large utility companies, with $w_{\text {pre }}^{\text {Inv }}$ chosen such that it is representative of the wealth of such a company ${ }^{8}$.

To ensure such a wealth figure returns reasonable results, we also calibrate this to levels of anticipated risk aversion. Hern et al. (2013) survey wind investors in the UK and find that switching from a Renewable Obligation Certificate (ROC) scheme to a FiT through Contracts for Difference (CfD), in essence a switch from incurring market price risk to incurring no market price risk, results in a $20 \%$ reduction in the expected rate of profitability for onshore wind. This gives a rough benchmark as to the premium required for incurring market price risk in wind investment. The findings of Hern et al. (2013) provide a useful calibration point, with a $w_{\text {pre }}^{\text {Inv }}$ value of $€ 18.98 \mathrm{bn}$ resulting. This also approximates expected levels of investor wealth.

Risk aversion parameters generally range from 0 (risk neutral) to 4 (extremely risk averse) for CRRA utility functions (Anderson and Dillon, 1992). Arrow (1965) assumes that risk aversion 'hovers about 1'. This is further evidence of an appropriate specification of risk aversion parameters as a change from a policy of constant premium to fixed price requires a c. $20 \%$ premium on investment when the risk aversion parameter is 1 . Alternate levels of risk aversion are catered for by a wide range of risk aversion parameters. We also carry out a sensitivity analysis with respect to the $w_{\text {pre }}^{\text {Inv }}$ parameter to capture further degrees of risk aversion. Section 5.1 discusses the impli-

\footnotetext{
${ }^{7}$ The total discounted value of electricity generated in the Irish Single Electricity Market came to $€ 2.9 \mathrm{bn}$ in 2011 (SEMO, 2015). Accounting for the rate of growth in electricity prices assumed by (Farrell et al., 2017) and discounting according to a $6 \%$ discount rate, this results in a total discounted value of c. $€ 37 \mathrm{bn}$.

${ }^{8}$ One such company is SSE who report an annual profit of $£ 1.564$ bn in 2014/2015 (SSE, 2015). Extrapolating this over 20 years, assuming an average exchange rate of $£ 1=€ 1.2$ and discounting according to a $6 \%$ discount rate, this returns a value of $€ 21.22 \mathrm{bn}$.
} 
cations of different risk aversion parameters to aid interpretation in the context of alternate risk aversion assumptions.

\section{Results}

\subsection{Risk Aversion}

Before we solve the overall optimisation problem, we first present quantified representations of risk aversion to aid interpretation of policy choice results. Table 5 shows the CE of 20-year discounted policy cost under different levels of risk aversion $(\beta)$ for a shared upside policy with a fixed $\theta=1$. When $\beta=0$, the $\mathrm{CE}$ is the same as the expected value of remuneration, i.e., the policymaker's expected cost. One can see that as the risk aversion parameter $\beta$ grows, the CE grows also as the policymaker is willing to incur a greater certain policy cost in order to forego a given level of cost uncertainty. When a $\beta$ parameter of 1 is in place, the policymaker is willing to take a certain cost that is $1.36 \%$ higher to forego the possibility of incurring extremely high policy cost. One can see that this threshold increases as the policymaker's level of risk aversion grows, with a $\beta$ value of 4 implying that a policymaker is indifferent between incurring the uncertain policy cost and a certain payment that is $5.527 \%$ greater than the expected value (i.e. $\beta=0$ ).

Table 5: Certainty equivalent of 20-year discounted policy cost by level of risk aversion $(\beta)$

\begin{tabular}{lrrrrr}
\hline$\beta$ & 0 & 1 & 2 & 3 & 4 \\
\hline Certainty Equivalent $(€)$ & $3.252 \mathrm{bn}$ & $3.296 \mathrm{bn}$ & $3.341 \mathrm{bn}$ & $3.386 \mathrm{bn}$ & $3.432 \mathrm{bn}$ \\
Increase relative to $\beta=0$ & 0 & $1.367 \%$ & $2.745 \%$ & $4.132 \%$ & $5.527 \%$ \\
\hline
\end{tabular}

To understand investor risk aversion, Figure 2 compares the change in Expected Money Value (EMV) required by an investor under different $\alpha$ risk aversion parameters as a result of switching from a fixed price policy $(\theta=0)$ to varying degrees of shared upside and a constant premium. One can see that when $\alpha=1$, EMV must be c. $20 \%$ greater for investment under a constant premium. This corresponds to the added remuneration quoted by Hern et al. (2013) and thus provides a suitable benchmark rate of investor risk aversion. One can see that the risk-sharing properties of the shared upside policies result in a much lower additional level of remuneration than the constant premium regime. However, EMV is still c.5-10\% greater than when $\theta=0$. These rates of risk aversion are given greatest attention in this analysis. Section 5.3.1 presents results relative to alternate ranges of risk aversion.

\subsection{Optimal policy choice}

We identify optimal levels of market price risk division both within and between policy types. This is first carried out for the discussed baseline parameters, followed by a sensitivity analysis 


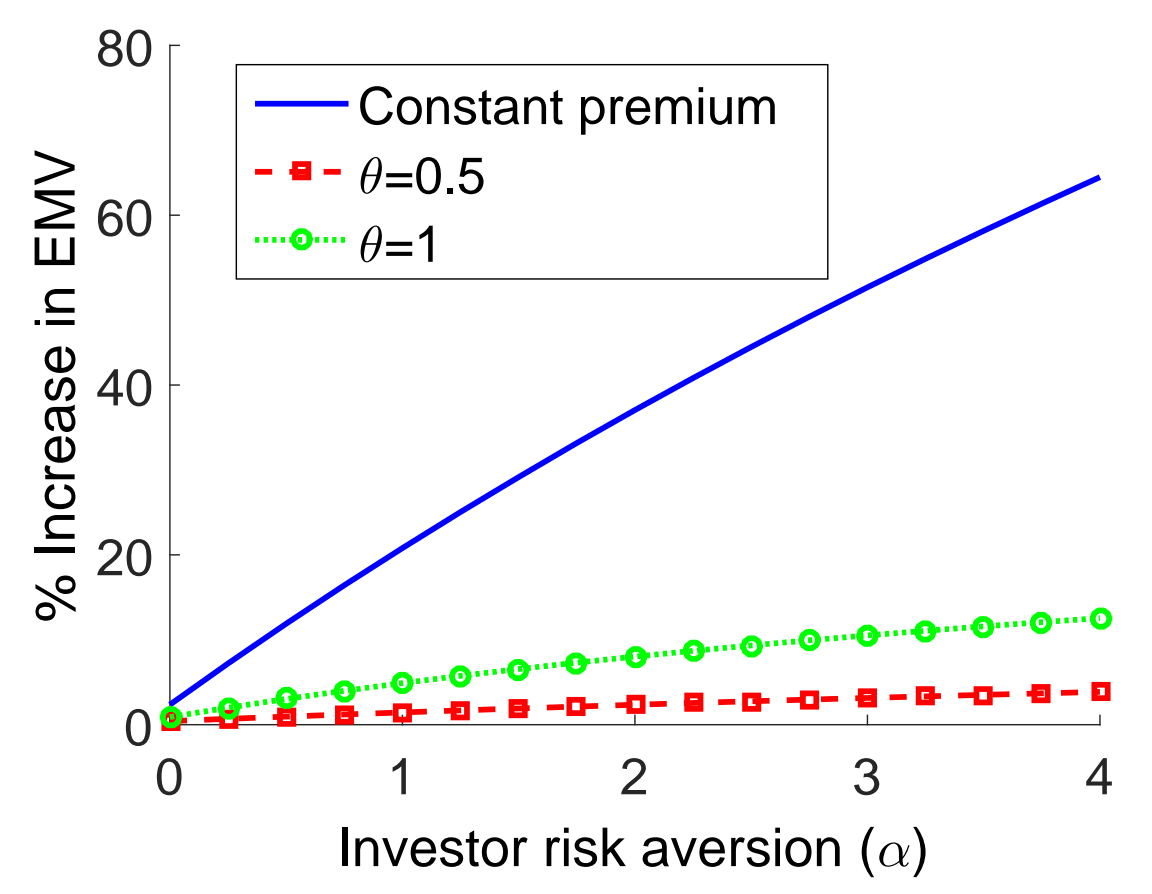

Figure 2: Quantification of Investor Risk Aversion

with respect to the calibrated degree of risk aversion. Quantifying such sensitivity gives insight into what FiT policy designs may be optimal when parameters differ from our baseline assumptions. The results of Table 5 and Figure 2 may be used to aid interpretation of risk aversion parameters in the baseline discussion that follows.

\subsubsection{Optimal Constant Premium Policy}

In this section the optimisation problem (equations (20) - (22)) is solved assuming the constant premium policy is the FiT, i.e., the FiT and its associated costs are determined by equations (3) and (4) respectively. The problem is solved 17 times, each time with a different level of investor risk aversion $(\alpha)$ from the set $\{0,0.25, . ., 4\}$. Optimal constant premium policies are insensitive to the degree of policymaker risk aversion as the policymaker does not incur any market price risk. Differences in FiT prices offered are thus entirely determined by the risk premium required by investors. Figure 3 shows that the pattern of optimality follows an increasing and concave trend. For each additional degree of investor risk aversion, a considerable increase in remuneration is required. For the baseline parameters, the required premium grows from $€ 23.1 / \mathrm{MWh}$ when $\alpha=0$, to to $€ 25.5 / \mathrm{MWh}$ when $\alpha=1$. This rises to $€ 30.8 / \mathrm{MWh}$ when $\alpha$ rises to 4 . This is due to the fact that investors must bear all market price risk under a constant premium regime. 


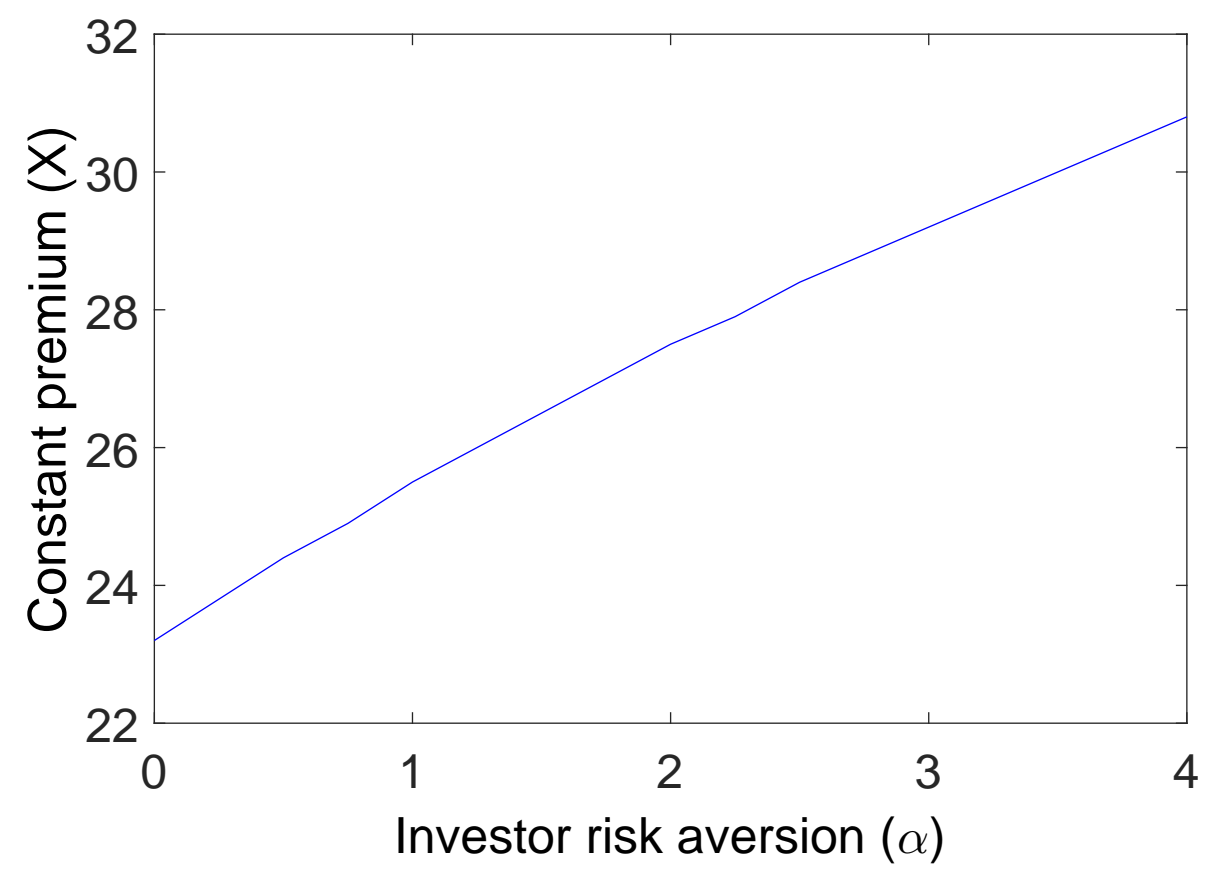

Figure 3: Optimal constant premium $X$ values (€/MWh) required in addition to the prevailing market price for each value of $\alpha$.

\subsubsection{Optimal shared upside policy}

In this section, the optimisation problem for the Stackelberg game (equations (20) - (22)) is solved with 17 different investor risk aversion levels $(\alpha=0,0.25, . ., 4)$ and 17 different policymaker risk aversion levels $(\beta=0,0.25, . ., 4)$ with the problem being solved $17 \times 17=289$ times in total. The Feed-in Tariff assumed is the shared upside policy, i.e., the FiT and its associated costs are being determined by equations (5) and (6) respectively. Figures 4(a) and 4(b) show the optimal price floor $(K)$ and corresponding share of market upside $(\theta)$ respectively for each $\alpha$ and $\beta$ combination. We find an inverse relationship where a larger share of market upside $(\theta)$ results in a smaller price floor $(K)$.

These figures shows that the optimal division of market price risk is primarily a function of the relative balance of risk aversion. If investors have very low level of risk aversion, $(\alpha \leq 0.25)$ and policymakers are extremely risk averse, it is optimal for investors to bear the greatest share of market price risk through a price floor regime. Similarly, if policymakers have a low level of risk aversion $(\beta \leq 0.25)$, a fixed price regime $(\theta=0)$ is optimal. Figure 4 (a) shows that intermediate policies $(0<\theta<1)$ are optimal when both investors and policymakers have similar degrees of risk aversion. We see that should investors and policymakers have an equal degree of risk aversion, a lower $\theta$ value is optimal, indicating that investors are more dominant. Indeed, it is only when investors have an extremely low level of risk aversion $(\alpha \leq 1)$ that a price floor policy $(\theta=0)$ 


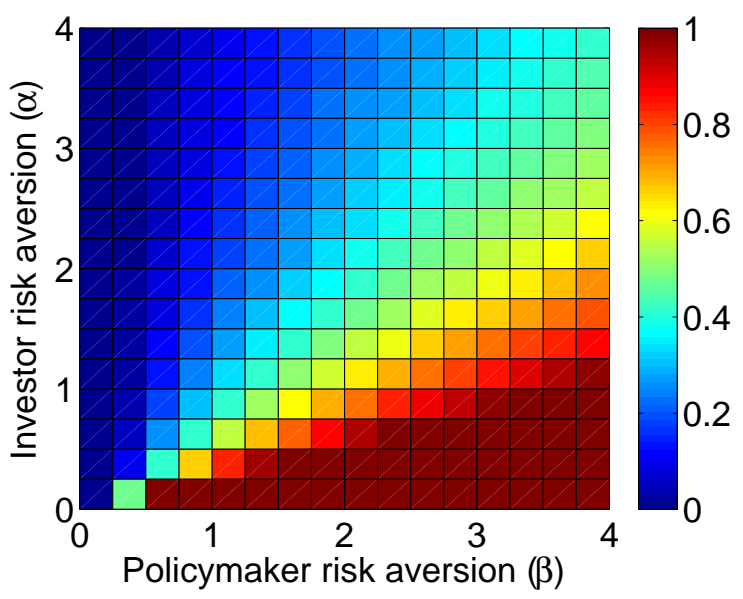

(a) Optimal $\theta(\%)$

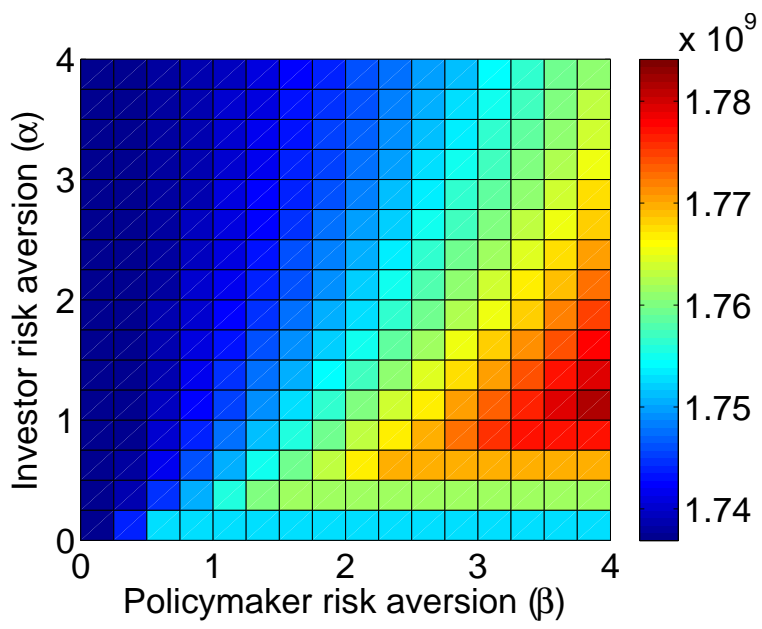

(c) CE of Investor Profit (€)

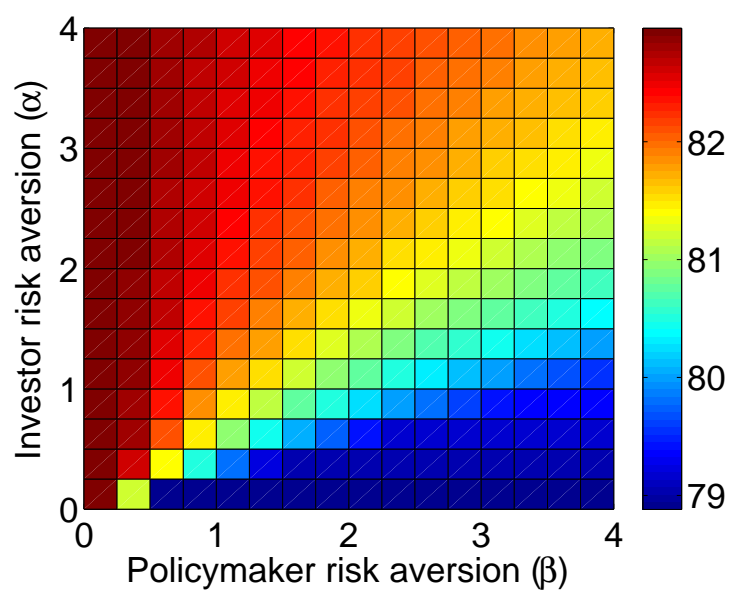

(b) Optimal $K(€ / \mathrm{MWh})$

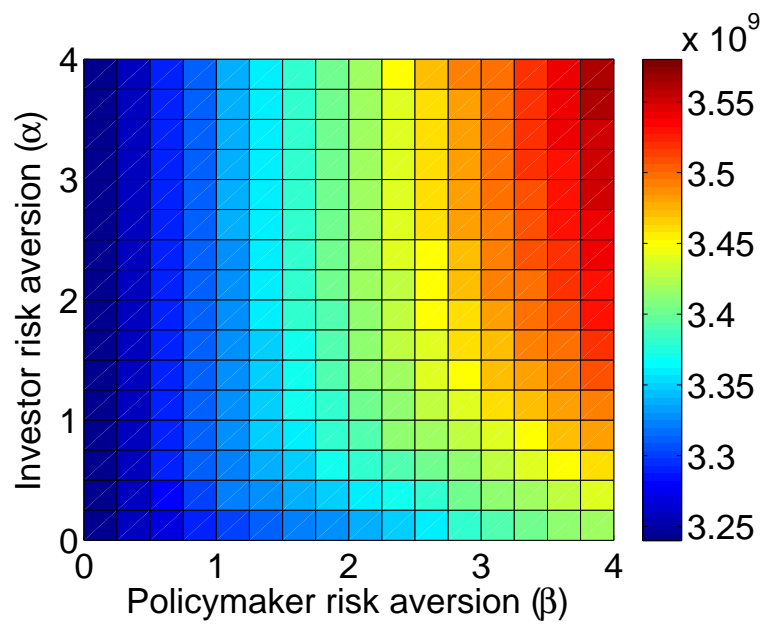

(d) CE of Policy Cost (€)

Figure 4: Optimal shared upside specifications for each $\alpha / \beta$ combination. Figures 4(a) and (b) display optimal $\theta$ (share of market upside going to investor) and $K$ (price floor), respectively. Figure 4(c) and (d) show the Certainty Equivalent of investor profit and policy cost respectively. 
is optimal. For this to occur, the magnitude of policymaker risk aversion must be in the region of three times greater than investors' risk aversion.

Figures 4(c) and 4(d) show investors' and policymaker's CE respectively which give insight into the additional remuneration required for the risk borne by each party under each $\alpha / \beta$ combination. Interestingly, we see different patterns for investor and policymaker risk.

In Figure 4(c) we see that additional investor remuneration to account for price risk is greatest when policymaker risk aversion is high (about 4) and investor risk aversion is about 1 . In such circumstances, the policymaker's preferences dominate those of the investor, and a $\theta$ close to 1 prevails. This requires investors to incur almost all market price risk. As this $\theta$ is higher than the $\theta$ obtained in situations where $\alpha$ is high, investors require a greater degree of additional remuneration to bear the additional risk.

Figure 4 (d) shows, as expected, that as the policymaker's risk aversion grows, the policymaker becomes more willing to incur a greater certain policy cost in order to forego a given level of cost uncertainty. It also shows that as investors' risk aversion grows, the policymaker becomes more willing to incur a greater certain policy cost in order to forego exposure to market price risk. This is because, when investors' risk aversion grows, the policymaker must accept more exposure to market price risk to ensure investors' meet the renewable energy target. This is despite the policymaker's own high level of risk aversion.

\subsubsection{Optimal cap \& floor policy}

In this section the optimisation problem is solved assuming the cap \& floor policy is the FiT, i.e., the FiT and its associated costs are being determined by equations (7) and (8) respectively. Figure 5(a) and Figure 5(b) show efficient cap $(\bar{S})$ and floor $(K)$ policies respectively, analogous to the results of Figures 4(a) and (b). To aid interpretation of the degree of market price variability that each party is exposed to under each policy, the difference between the cap and floor for $\alpha / \beta$ combination is displayed in Figure 5(d). Analysing these results indicates that the pattern of optimality for cap and floor policies follows a similar trend to that of the shared upside policy.

However, one difference may be observed. For each $\alpha / \beta$ combination that involves investors receiving market upside (i.e., $\theta>0$ or $\bar{S}>K$ ), cap \& floor policies require a slightly lower efficient price floor. This is due to differences in the pattern of risk sharing between policies and the attitudes of each party to such differences. A shared upside policy offers a portion of all market prices in excess of an efficient floor, whilst a cap \& floor policy offers market prices, in their entirety, in excess of the floor and as far as a certain threshold (cap). Each market price has a probability of occurrence, with lower prices having a greater probability than higher prices. As a result of these differences, cap \& floor policies have a greater emphasis on prices that are more likely to occur. This improves the EMV of remuneration for a cap \& floor regime relative to a 


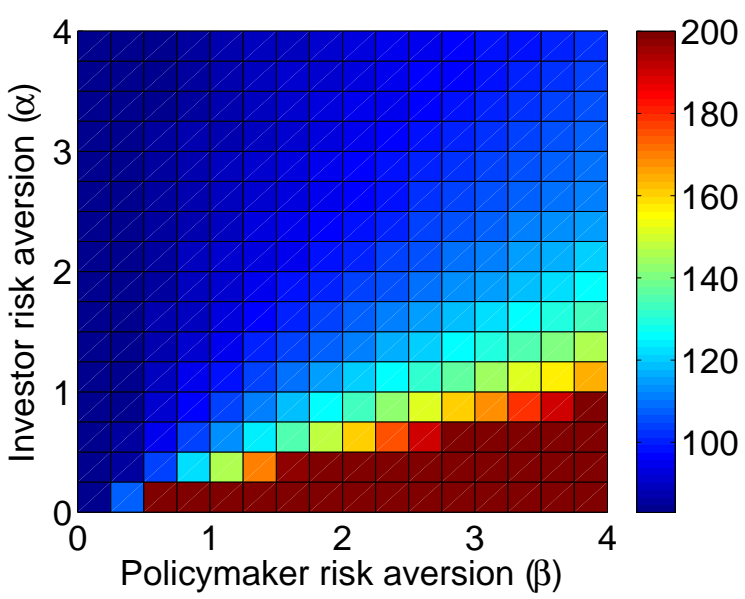

(a) Optimal Cap $\bar{S}(€ / \mathrm{MWh})$

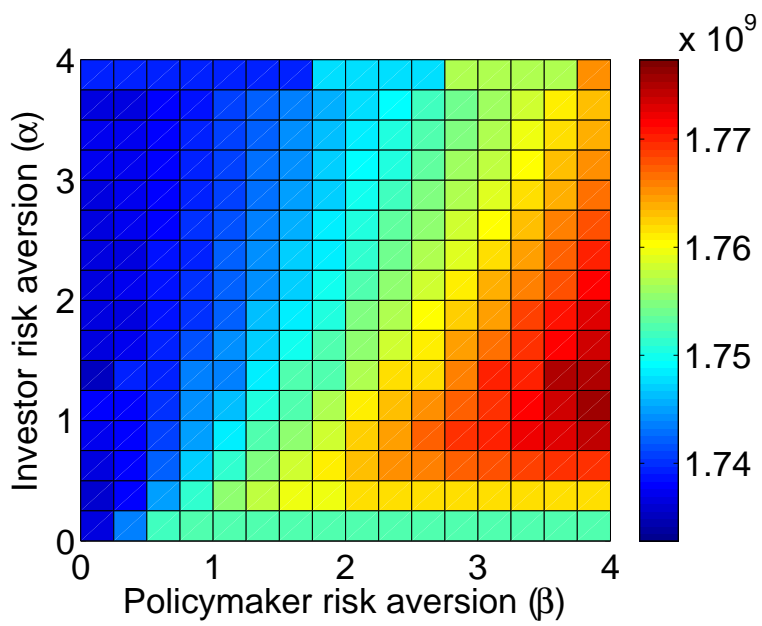

(c) CE of Investor Profit $(€)$

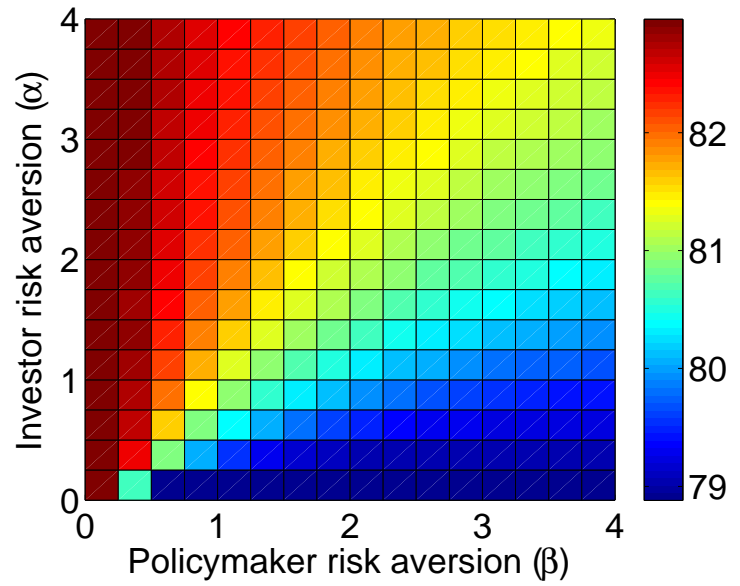

(b) Optimal Floor $K(€ / \mathrm{MWh})$

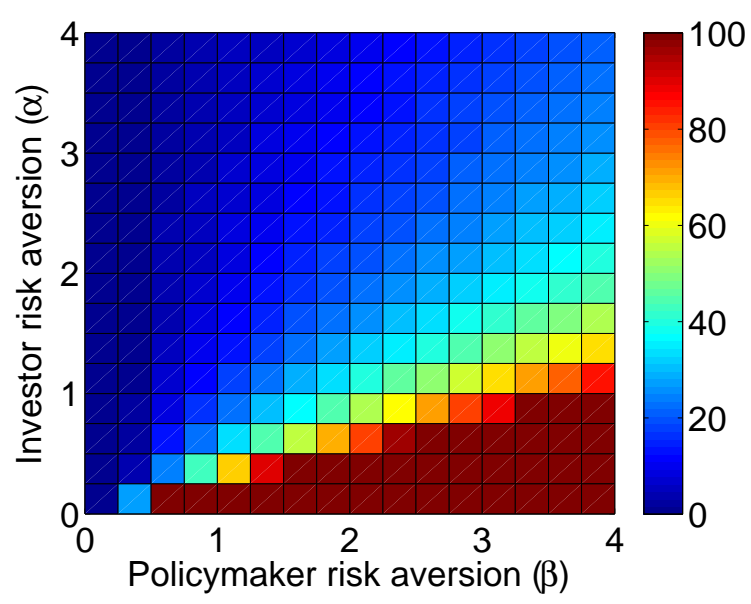

(d) Difference between cap and floor (€/MWh)

Figure 5: Optimal cap \& floor specifications for each $\alpha \backslash \beta$ combination. Figures 5(a) and 5(b) respectively display optimal $\bar{S}$ (price cap) and $K$ (price floor). The $\bar{S}$ value of '200' in Figure 5(a) denotes all values $\geq 200$. Figure 5(c) shows the Certainty Equivalent of investor profit while Figure 5(d) shows the difference between the cap and floor under each regime, with '100' denoting all values $\geq 100$. 
shared upside regime and the required efficient price floor is slightly lower.

These effects are most evident when one examines Figure 5(c) where the investors' CE follows a similar trend to the shared upside policy, but is of a modestly lesser amount. This difference reflects the investors' aversion to greater reliance on market remuneration that is more uncertain. The slightly lower price floor for a cap \& floor regime reflects the small difference in market price risk that must be borne relative to a shared upside policy.

The purpose of this model is to compare efficiently specified FiTs and does not capture FiT misspecification. However, Farrell et al. (2017) illustrate a further benefit of cap \& floor regimes in this regard. Greater protection against FiT misspecification may be offered by a cap and floor regime, where policymakers are protected against offering over-remuneration should market prices exceed the cap to a degree that is greater than expected. This characteristic may affect the choice between policy options, alongside the differences outlined when FiTs are efficiently specified.

\subsubsection{Comparing Policies}

As discussed, the EMV and CE of investor remuneration vary to reflect the additional remuneration required to account for different levels of risk aversion. Similarly, the utility of the policymaker will vary according to the EMV outlay required. As expected policy cost and utility of policy cost (i.e., incorporating risk exposure) are both of concern for policy decisions, policy choice will be discussed in terms of both EMV and the utility equivalent.

Using the results from Sections 5.2.2 and 5.2.3, Figure 6(a) displays the difference in expected policy cost between shared upside and cap \& floor policies for different $\alpha$ and $\beta$ combinations. It shows that for most combinations, there is no difference in EMV between the two policies. However, when the policymaker risk aversion parameter is 2 or greater, there are modest differences in expected policy cost between the two policies. As Section 5.2.3 discussed, when investors receive some market upside, the price floor $K$ is lower for a cap \& floor policy as investors receive all upside immediately in excess of the guaranteed minimum. This effect is exaggerated when the efficient price floor is lower due to a high degree of market upside being offered to investors. In such circumstances, a marginal reduction in the price floor has a greater impact on expected policy cost, as the foregone market remuneration has a higher probability of occurring. As such, the reduced cost of a cap \& floor policy, relative to a shared upside policy, is greater when a greater share of market upside is offered to investors. However, this only prevails when $\alpha>0$ as the pattern of market price risk, and thus the difference in resulting utility, only occurs when investors are risk averse. When investors are risk neutral, they are indifferent to the pattern of remuneration and thus any difference in policy cost is negligible.

Using the results from Sections 5.2.3 and 5.2.1, the difference in expected policy cost between the cap \& floor and constant premium policies is displayed in Figure 6(b). Constant premium 


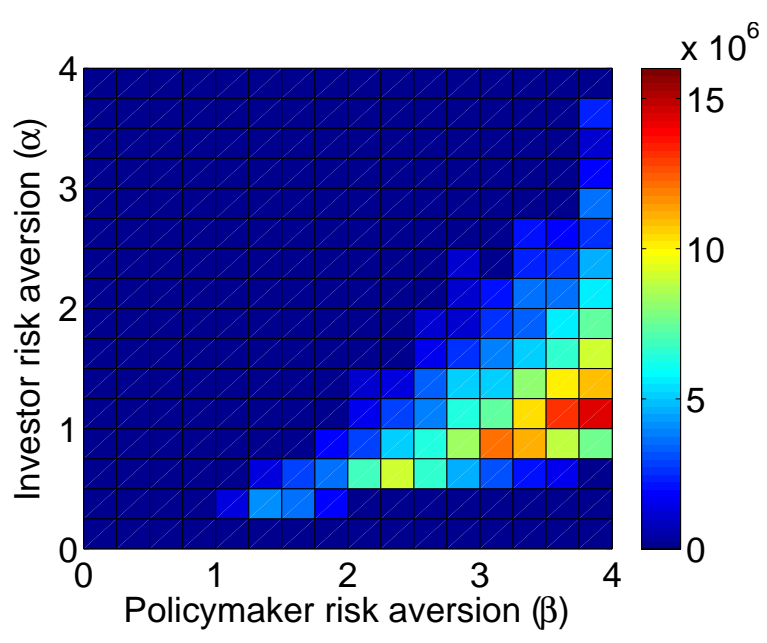

(a) Shared upside cost less cap \& floor cost $(€)$

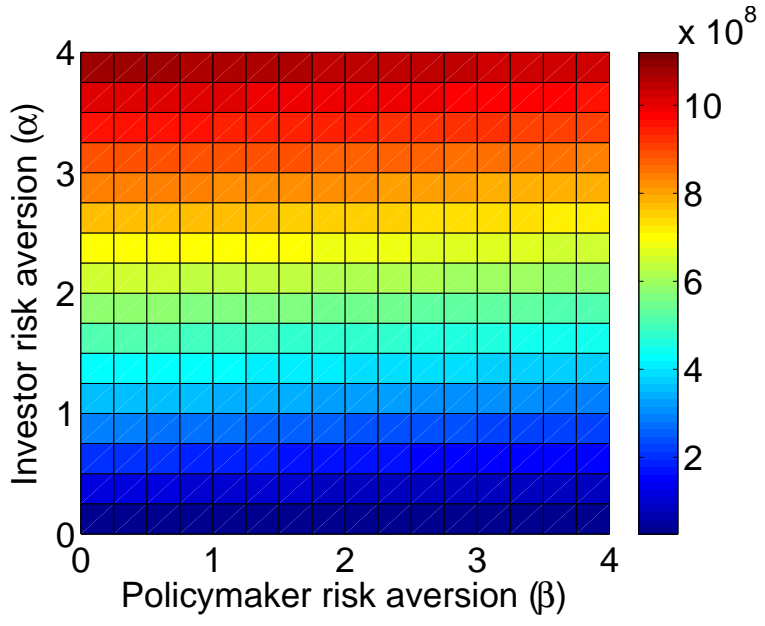

(b) Constant premium cost less cap \& floor cost $(€)$

Figure 6: Difference in EMV policy cost for each $\alpha / \beta$ combination.

policies have a similar cost (c. $1.27 \%$ more expensive) to cap \& floor policies when the investors are risk neutral $(\alpha=0)$. This differences rises to $32 \%$ when investors have a risk aversion parameter of $\alpha=4$. Although a higher $\beta$ yields a lower cap $\&$ floor policy cost and thus widens the gap to the constant premium cost, this is not apparent in Figure 6 (b) as this difference is greatly overshadowed by the differences between investor risk aversion parameters.

For shared upside and cap \& floor policies, policymaker utility is very similar, with an absolute difference of 0.00-0.07\% observed in the numerical simulations. As such, the discussed differences in expected cost may be more important when deciding between a cap \& floor or shared upside regimes. Utility-based analyses are more appropriate for determining an efficient within-policy cap \& floor or shared upside specification.

However, the utility derived from a constant premium policy differs greatly to that for a shared upside or cap \& floor policy. Policymaker utility under a shared upside or cap \& floor policy may be up to $7 \%$ more than for a constant premium policy. Using the results from Sections 5.2.2 5.2.1, Figure 7 compares policymaker's utility under cap \& floor/shared upside policy with the utility under a constant premium policy. It displays the Feed-in Tariff policy with the highest policymaker utility for each $\alpha / \beta$ combination. We see that a constant premium policy results in a greater level of utility for the policymaker when $\alpha \leq 0.5$ and $\beta \geq 0.75$. As expected levels of risk aversion hover about 1 , this would suggest that investors must be indifferent to risk for a constant premium policy to be optimal. This is an important finding in relation to the common use of constant premium policies in many jurisdictions. This results suggests that for such policies to be optimal, policymakers must be more than four times as risk averse as investors. 


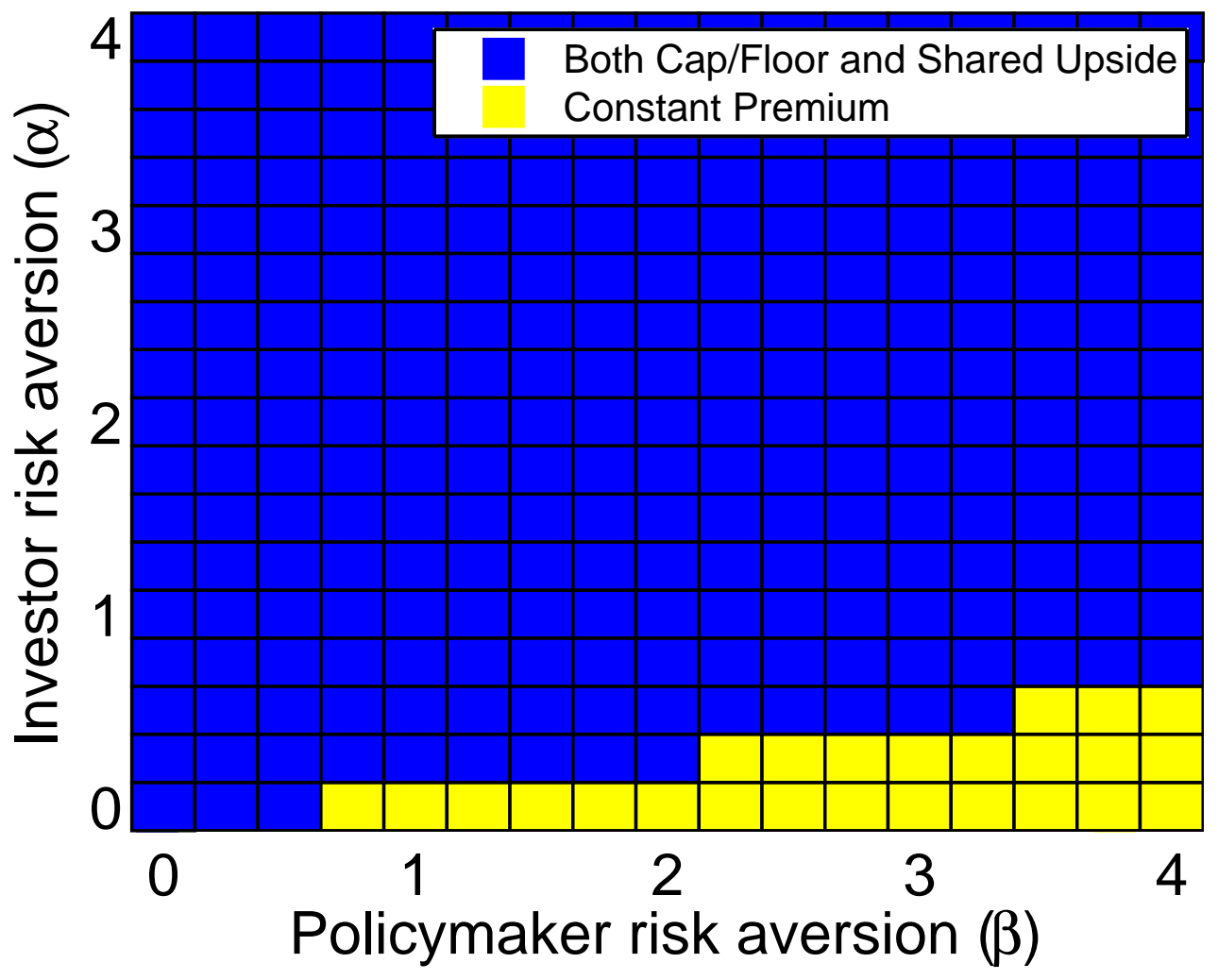

Figure 7: Policymaker preference: the policy choice which yields the greatest utility for the policymaker for different combinations of $\alpha$ and $\beta$. The difference in utility between cap \& floor and shared upside policies is $\leq 0.07 \%$ and thus these are assumed to be equal. Blue represents when cap \& floor/shared upside policies are optimal while yellow represents when the constant premium policy is optimal. 


\subsubsection{Summary of baseline results}

This section has shown that intermediate divisions of market price risk are optimal when investor and policymaker risk aversion is of a similar magnitude. On utility grounds, both shared upside and cap \& floor regimes return similar values for our baseline parameters. However, cap \& floor policies have a lower EMV cost when policymakers are highly risk averse and high levels of market upside are offered to investors. Constant premium policies are considerably more expensive than both shared upside and cap \& floor policies in EMV terms. However, a constant premium policy may be preferred on utility grounds when investor's risk aversion is $\leq 0.5$ and policymakers have risk aversion parameters in the region of 0.75 or greater.

\subsection{Sensitivity analysis}

Different levels of calibrated risk aversion (pre-existing wealth levels) may result in different degrees of optimal market price risk apportionment. If FiT policy comprises a greater share of total electricity cost, policymakers may be more sensitive to bearing market price risk. Similarly, investor sensitivity may increase if they have a less diversified portfolio of investments and thus require a higher EMV in order to incentivise investment. This section informs policy as to optimal FiT choice under different levels of calibrated risk aversion. We model greater risk sensitivity by halving the policymaker's baseline pre-existing wealth parameter ( $w_{\text {pre }}^{\text {policy }}$ ) and model lesser sensitivity by doubling it. 'Low sensitivity' results are calculated where the calibration parameter is double the baseline level while 'High sensitivity' results are calculated where the calibration parameter is half the baseline level.

\subsubsection{Changes in the calibrated rate of policymaker risk aversion}

Figure 8 shows the optimal between-tariff FiT policy choice, in terms of highest utility. Under each level of pre-existing wealth for the policymaker, constant premium policies are only optimal when policymaker risk aversion is greater than investor risk aversion. Figure 8 shows that when policymakers are less sensitive to risk, perhaps when renewables comprise a small proportion of total electricity cost, constant premium policies are only optimal when investors are risk neutral. When policymakers are highly sensitive, we find that constant premium policies are optimal when investor risk aversion is around half that of policymaker risk aversion. As such, constant premium policies are of increasing importance as the burden of renewables policy increases. However, even with a doubling of the level of underlying sensitivity, constant premium policies are only optimal when policymaker risk aversion is much greater than investor risk aversion.

Figure 9 displays the optimal division of market price risk (i.e., values of $\theta$ ) when the shared upside policy is chosen. For brevity of presentation, within tariff-choice is presented in the context of a shared upside policy only. Inferences as to the equivalent cap and floor policy may be identified with reference to the relationships illustrated by Figures 4 and 5 . When policymaker sensitivity 


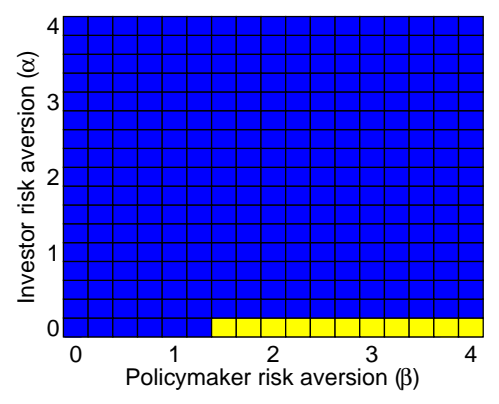

(a) Low sensitivity

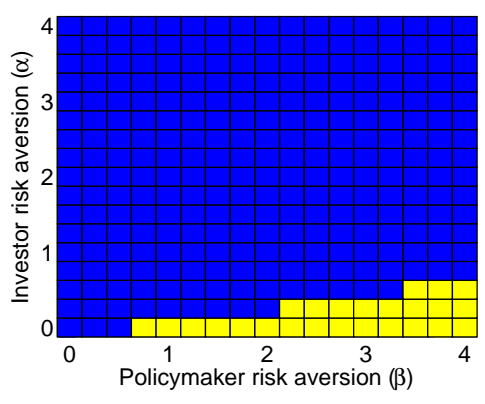

(b) Baseline

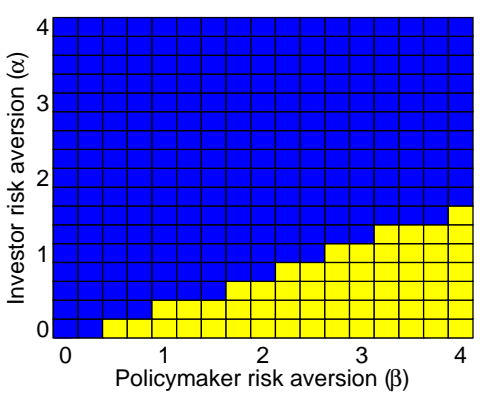

(c) High sensitivity

Figure 8: Between-tariff optimality for different sensitives of policymaker pre-existing wealth. Difference in utility between cap \& floor and shared upside policies is $\leq 0.03 \%$ and thus these are assumed to be equal. Blue represents when cap \& floor/shared upside policies are optimal while yellow represents when the constant premium policy is optimal.

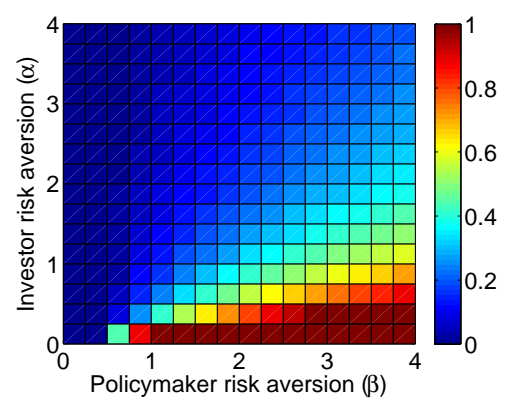

(a) Low sensitivity

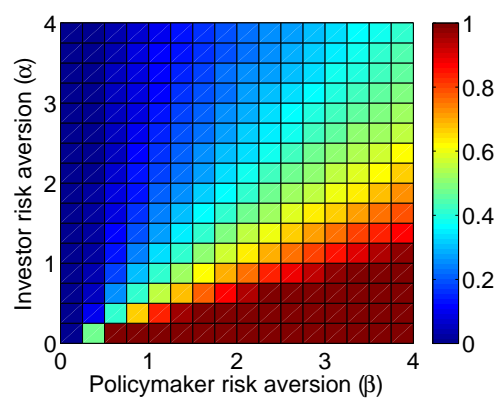

(b) Baseline

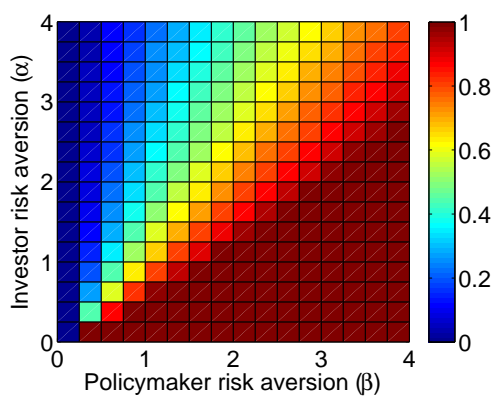

(c) High sensitivity

Figure 9: Within-tariff division of market price risk using the shared upside regime (i.e., values of $\theta(\%)$ ) for different sensitives of policymaker pre-existing wealth. 
is low, a flat rate FiT $(\theta=0)$ or low share of market upside for investors is generally optimal, hence, market price risk is transferred from the investors to the policymaker. When policymakers are highly sensitive to market price risk, a higher $\theta$ value and thus lower $K$ guarantee is required for efficient division of market price risk. This transfers market price risk from the policymaker to the investors. Such changes in sensitivity may occur due to an increasing renewables subsidy burden as deployment progresses. For prudent forward-looking policymakers, this finding shows that flexibility is required in legislative frameworks, such that divisions of market price risk may be augmented to accommodate this evolving optimality.

A further sensitivity analysis examining the investors' sensitivity to calibrated levels of risk aversion is also presented in Appendix A. This sensitivity analysis provides similar results to this section: as investors become less sensitive to market price risk, the scope for constant premium FiTs increases while higher values of $\theta$, and thus lower values of $K$, are optimal for the efficient division of market price risk. Further sensitivity analyses were also performed by varying the rate of growth and volatility parameters in the Geometric Brownian Motion market price process. These results did not significantly impact the conclusions of the work which will now be discussed.

\section{Discussion and Conclusion}

Feed-in Tariffs are a favoured renewable energy support scheme due to their ability to mitigate market price risk for potential investors. This risk is transfered through a policymaker to a counterparty, often the consumer. Different FiT designs transfer this risk in different ways. This paper has contextualised the optimal use of each FiT design with respect to investor and policymaker exposure to market price risk.

Optimal FiTs are identified by setting up renewable energy investment as a strategic leader game. Investors install a given quantity in order to maximise utility, with policymakers anticipating this response and specifying a FiT price to meet policy targets. Risk aversion is modelled using a Constant Relative Risk Aversion (CRRA) utility specification, calibrated to degrees of risk aversion observed in the literature while the model is solved using Monte-Carlo simulations of market prices. Alternative levels of risk aversion are captured through a wide spectrum of risk aversion parameters and sensitivity analyses. We characterise the spectrum of market price risk division for three classes of FiT. We analyse constant premium, shared upside and cap \& floor policies alone and together.

For a stylised case study of the Irish electricity market, this paper provides a number of important contributions for policymakers when considering the most appropriate Feed-in Tariff choice:

1. We find that investor preferences are more influential than those of the policymaker when degrees of risk aversion are of a similar magnitude. 
2. Under our baseline assumptions, market price risk should be shared except under circumstances of extreme investor/consumer indifference to risk. This suggests that commonly employed fixed price and constant premium policies are sub-optimal unless investors or consumers are risk neutral.

3. We find that cap \& floor policies offer very similar levels of utility to shared upside policies. However, when policymakers are extremely risk averse and investors are modestly risk averse, the expected cost of the shared upside policy is slightly greater. This is because the different pattern of risk sharing requires a slightly lower minimum price guarantee under a cap \& floor regime.

4. In Expected Money Value (EMV) terms, constant premium policies are always more expensive than those that share market upside, but offer higher utility when policymakers are risk averse and investors have low levels of risk aversion.

Efficient division of market price risk is of increasing importance as renewables deployment grows and costs becomes a larger share of total electricity cost. For many risk aversion scenarios, the optimal division of market price risk transitions through a wide spectrum of possible levels as such sensitivity changes. This has implications for both current and future policymaking. For current policymaking, it suggests that an intermediate division of market price risk is most appropriate in the majority of circumstances. This casts doubt on the efficiency of commonly-employed constant premium or flat-price FiTs. Second, the findings of this paper suggest that consideration of optimal market price risk is of increasing importance as renewables deployment grows. Current policy should anticipate such a potential requirement and put in place flexible legislative measures to accommodate changes in market price risk division in future FiTs contracts, if required.

Renewables deployment has continued at great pace in many jurisdictions, with FiTs the predominant support measure and growing in influence. Cited as a hedge against fossil fuel market price fluctuations, the relative benefit of renewables has been under increasing strain with the international proliferation of low-cost unconventional gas and depressing effect this has had on electricity prices. Not only has this potentially reduced the hedge value of renewables, the potential risk of high subsidy cost has become a greater concern in many jurisdictions. Such concerns may grow with increasing renewables penetration. This paper presents a means for policymakers to consider environmental policy in the context of such risks. Through the simulation modelling framework presented, we provide an economic rationale for optimal FiT specification with which a policymaker may make a more informed decision as to both the level and format of a chosen FiT.

\section{Acknowledgements}

This work was funded under the Programme for Research in Third-Level Institutions (PRTLI) Cycle 5 and co-funded under the European Regional Development Fund (ERDF); Science Foun- 
dation Ireland awards 09/SRC/E1780 and 12/IA/1683. The authors would like to acknowledge two anonymous reviewers in addition to the ESRI's Energy Research Center, Seán Lyons, Valentin Bertsch (both ESRI) and James Gleeson (University of Limerick).

\section{Appendix A. Changes in the calibrated rate of investor risk aversion}

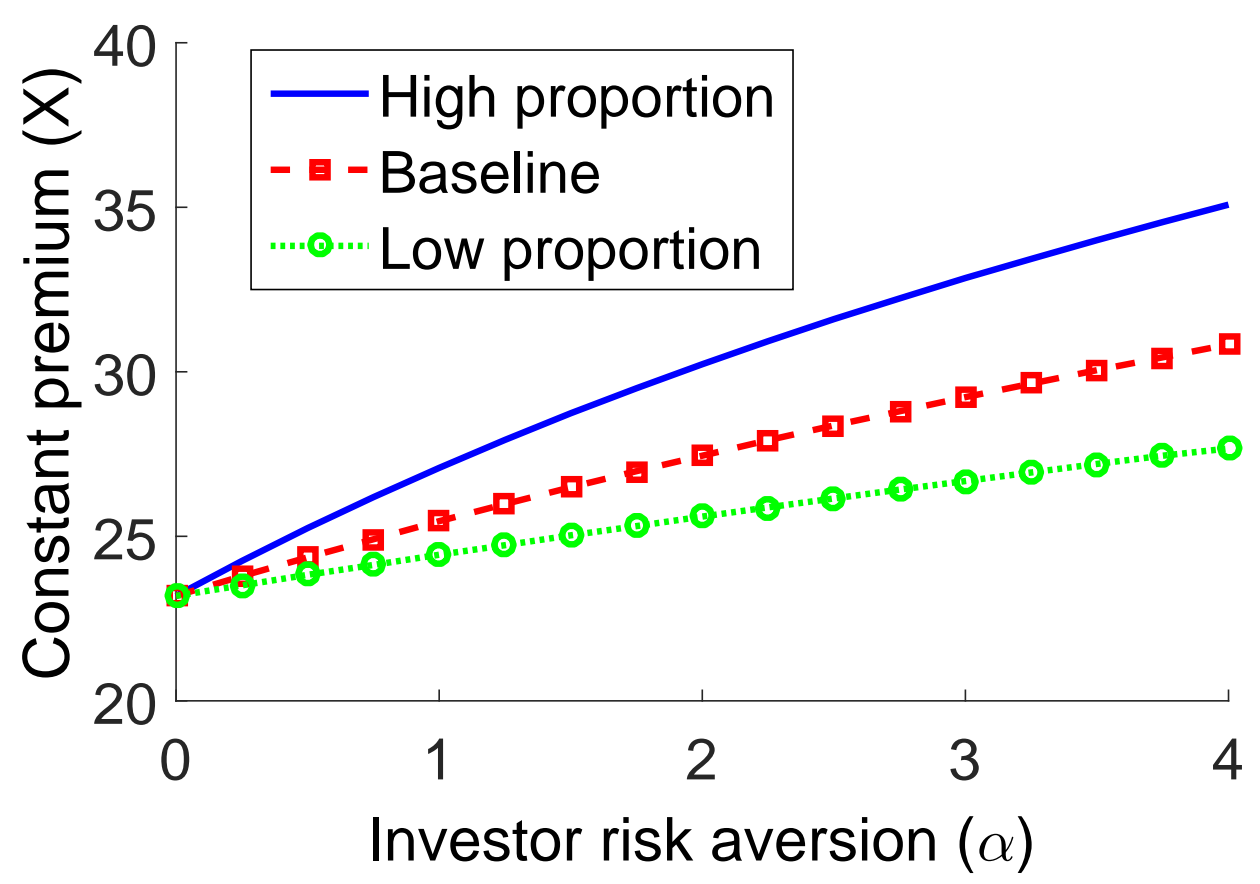

Figure A.10: Values for Optimal Constant Premium $X(€ / M W h)$ for different levels of investor risk sensitivity

This appendix follows from the analysis detailed in Section 5.3.1 and provides a sensitivity analysis for investors calibrated level of risk aversion. Unlike changes in policymaker risk sensitivity, optimal constant premium policies will change with changes in investor risk sensitivity. Figure A.10 shows that a greater constant premium $(X)$ is required as investor risk sensitivity grows, with this difference greater for higher levels of risk aversion.

Analysing between-policy FiT choice, Figure A.11 shows that as investors become more sensitive to market price risk, the scope for a constant premium FiT diminishes. This is in contrast to a changes in policymaker risk sensitivity. As renewables deployment matures, FiT costs are likely to comprise both a greater proportion of a policymaker's electricity budget and a lesser proportion of investors' budgets, as larger, less specialised developers who are more diversified may enter the industry. As such, investor risk aversion falls whilst policymaker risk aversion rises, suggesting that the scope for premium policies may grow as both sensitivity analyses would suggest. Indeed, if both investor sensitivity falls and policymaker sensitivity grows, the magnitude of this growth may of an even greater extent than that described. 


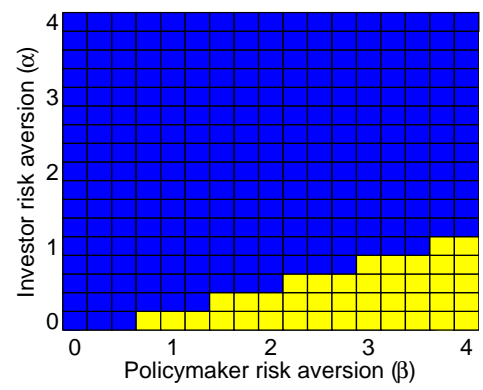

(a) Low sensitivity

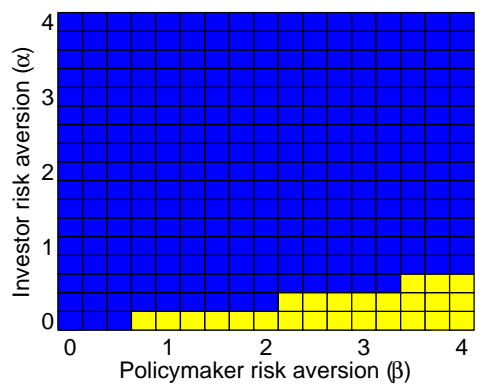

(b) Baseline

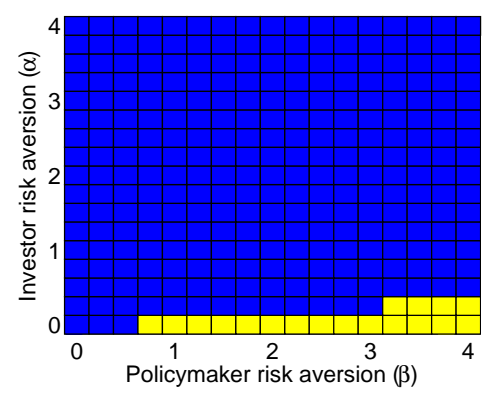

(c) High sensitivity

Figure A.11: Between-tariff optimality for different sensitives of investor risk aversion. Difference in utility between cap \& floor and shared upside policies is $\leq 0.03 \%$ and thus these are assumed to be equal. Blue represents when cap $\&$ floor/shared upside policies are optimal while yellow represents when the constant premium policy is optimal.

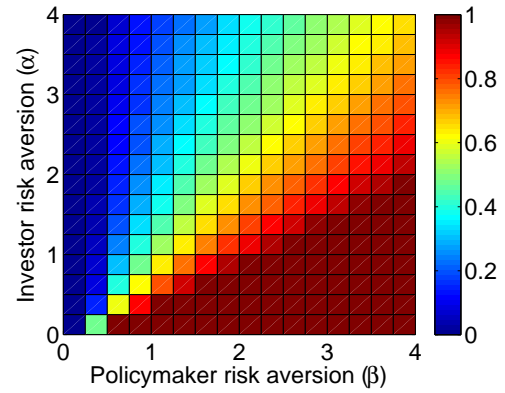

(a) Low sensitivity

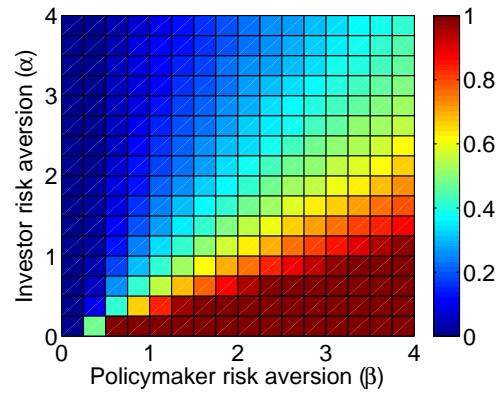

(b) Baseline

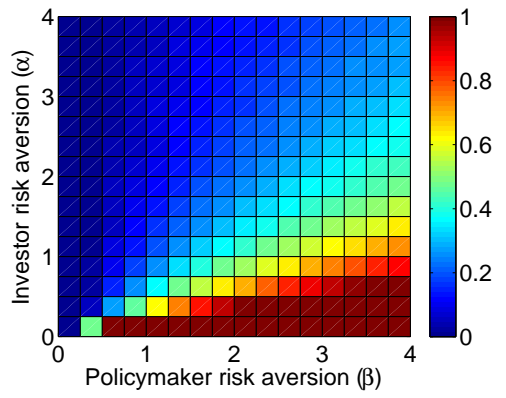

(c) High sensitivity

Figure A.12: Within-tariff division of market price risk using the shared upside regime (i.e., values of $\theta(\%)$ ) for different sensitives of investor risk aversion. 
Figure A.12 displays the optimal division of market price risk (i.e., values of $\theta$ ) when the shared upside policy is the chosen policy. When investor sensitivity is high, a flat rate FiT or low share of market upside for investors is generally optimal and market price risk is transferred from the investors to the policymaker. As investors become less sensitive to market price risk, a higher $\theta$ and thus lower $K$ guarantee is sufficient for efficient division of market price risk and hence, market price risk is transferred in the opposite direction.

\section{References}

Amde-Manesme, C.-O., Barthlmy, F., Prigent, J.-L., 2015. Real estate investment: Market volatility and optimal holding period under risk aversion. Economic Modelling, -.

URL http: / / www. sciencedirect.com/science/article/pii/s0264999315003296

Anderson, J. R., Dillon, J. L., 1992. Risk analysis in dryland farming systems. No. 2. Food \& Agriculture Org.

Arrow, K., 1971. Essays in the theory of risk-bearing. North-Holland.

Arrow, K. J., 1965. Aspects of the Theory of Risk-Bearing. Yrjö Jahnssonin Säätiö , Academic Bookstore, Helsinki.

Attema, A. E., Lugnér, A. K., Feenstra, T. L., 2010. Investment in antiviral drugs: a real options approach. Health economics 19 (10), 1240-1254.

Baron, D. P., 1970. Price uncertainty, utility, and industry equilibrium in pure competition. International Economic Review, 463-480.

Batlle, C., 2011. A method for allocating renewable energy source subsidies among final energy consumers. Energy Policy 39 (5), 2586 - 2595.

URL http: //www. sciencedirect.com/science/article/pii/s0301421511001078

Boomsma, T. K., Linnerud, K., 2015. Market and policy risk under different renewable electricity support schemes. Energy 89, 435-448.

Bryant, C., 2013. Soaring renewable energy costs set to stoke german energy debate. Financial Times.

Burer, M. J., Wustenhagen, R., 2009. Which renewable energy policy is a venture capitalist's best friend? empirical evidence from a survey of international cleantech investors. Energy Policy 37 (12), $4997-5006$.

URL http : //www.sciencedirect.com/science/article/pii/S0301421509004807 
Butler, L., Neuhoff, K., 2008. Comparison of feed-in tariff, quota and auction mechanisms to support wind power development. Renewable Energy 33 (8), 1854 - 1867.

URL http : //www.sciencedirect.com/science/article/pii/S0960148107003242

Chang, M.-C., Hu, J.-L., Han, T.-F., 2013. An analysis of a feed-in tariff in taiwans electricity market. International Journal of Electrical Power \& Energy Systems 44 (1), 916-920.

URL http : //linkinghub.elsevier.com/retrieve/pii/S0142061512004863

Chawla, M., Pollitt, M. G., 2013. Energy-efficiency and environmental policies \& income supplements in the uk: evolution and distributional impacts on domestic energy bills. Economics of Energy \& Environmental Policy 2 (1).

Chiu, M. C., Wong, H. Y., 2013. Optimal investment for an insurer with cointegrated assets: CRRA utility. Insurance: Mathematics and Economics 52 (1), 52 - 64.

URL http: //www. sciencedirect.com/science/article/pii/s0167668712001424

Chronopoulos, M., Reyck, B. D., Siddiqui, A., 2014. Duopolistic competition under risk aversion and uncertainty. European Journal of Operational Research 236 (2), 643 - 656.

URL http: //wWw. sciencedirect.com/science/article/pii/s0377221714000393

Chunxiang, A., Li, Z., Wang, F., 2016. Optimal investment strategy under time-inconsistent preferences and high-water mark contract. Operations Research Letters 44 (2), $212-218$.

URL http: //www.sciencedirect.com/science/article/pii/s0167637715001728

Cotter, J., Hanly, J., 2012. A utility based approach to energy hedging. Energy Economics 34 (3), 817-827.

URL http : //ideas.repec.org/a/eee/eneeco/v34y2012i3p817 - 827.html

Couture, T., Gagnon, Y., 2010. An analysis of feed-in tariff remuneration models: Implications for renewable energy investment. Energy Policy 38 (2), 955-965.

URL http : //linkinghub.elsevier.com/retrieve/pii/S0301421509007940

DCCAE, 2009. Ireland's National Renewable Energy Action Plan.

URL http : //www.dccae.gov.ie/energy/SiteCollectionDocuments/Renewable Energy/The\%20National\%20Renewable\%20Energy\%20Action\%20Plan\%20(PDF).pdf

Del Rio, P., Mir-Artigues, P., 2012. Support for solar pv deployment in spain: Some policy lessons. Renewable and Sustainable Energy Reviews 16 (8), 5557-5566.

Devitt, C., Malaguzzi Valeri, L., 2011. The effect of REFIT on Irish wholesale electricity prices. The Economic and Social Review 42 (3), 343369.

URL http : //ideas.repec.org/a/eso/journl/v42y2011i3p343 - 369.html 
Dinica, V., 2006. Support systems for the diffusion of renewable energy technologies-an investor perspective. Energy Policy 34 (4), $461-480$.

URL http : //www.sciencedirect.com/science/article/pii/S0301421504001880

Doherty, R., O’Malley, M., 2011. The efficiency of Ireland's Renewable Energy Feed-In Tariff (REFIT) for wind generation. Energy Policy 39 (9), 4911-4919.

URL http : //linkinghub.elsevier.com/retrieve/pii/S0301421511004800

Dong, C., 2012. Feed-in tariff vs. renewable portfolio standard: An empirical test of their relative effectiveness in promoting wind capacity development. Energy Policy 42 (0), 476 - 485.

URL http : //www.sciencedirect.com/science/article/pii/S0301421511010068

DW, 2013. German energy transition caught in subsidies' trap. DW.de.

Ekins, P., 2004. Step changes for decarbonising the energy system: research needs for renewables, energy efficiency and nuclear power. Energy Policy 32 (17), 1891-1904.

URL http : //linkinghub.elsevier.com/retrieve/pii/S0301421504000692

Fagiani, R., Barqun, J., Hakvoort, R., 2013. Risk-based assessment of the cost-efficiency and the effectivity of renewable energy support schemes: Certificate markets versus feed-in tariffs. Energy Policy 55, 648-661.

URL http : //linkinghub.elsevier.com/retrieve/pii/S0301421512011330

Falconett, I., Nagasaka, K., 2010. Comparative analysis of support mechanisms for renewable energy technologies using probability distributions. Renewable Energy 35 (6), 1135 - 1144.

URL http : //www.sciencedirect.com/science/article/pii/S0960148109004959

Fan, L., Hobbs, B. F., Norman, C. S., 2010. Risk aversion and $\mathrm{CO}_{2}$ regulatory uncertainty in power generation investment: Policy and modeling implications. Journal of Environmental Economics and Management 60 (3), 193 - 208.

URL http://www. sciencedirect.com/science/article/pii/s009506961000080X

Fan, L., Norman, C. S., Patt, A. G., 2012. Electricity capacity investment under risk aversion: A case study of coal, gas, and concentrated solar power. Energy Economics 34 (1), 54 - 61.

URL http://www. sciencedirect.com/science/article/pii/s014098831100260X

Farrell, N., Devine, M., Lee, W., Gleeson, J., Lyons, S., 2017. Specifying An Efficient Renewable Energy Feed-in Tariff. Energy Journal 38 (2).

Farrell, N., Lyons, S., 2015. Who should pay for renewable energy? comparing the household impacts of different policy mechanisms in ireland. Energy Research \& Social Science 7, 31 - 42. URL http: //www. sciencedirect.com/science/article/pii/s2214629615000262 
Feng, Z.-H., Wei, Y.-M., Wang, K., 2012. Estimating risk for the carbon market via extreme value theory: An empirical analysis of the EU ETS. Applied Energy 99, 97 - 108.

URL http: //www.sciencedirect.com/science/article/pii/s0306261912000761

Fleten, S.-E., Maribu, K., Wangensteen, I., 2007. Optimal investment strategies in decentralized renewable power generation under uncertainty. Energy 32 (5), $803-815$.

URL http://www.sciencedirect.com/science/article/pii/s0360544206001150

Fudenberg, D., Tirole, J., 1991. Game theory. MIT Press, Cambridge, Massachusetts.

Gabriel, S. A., Conejo, A. J., Fuller, J. D., Hobbs, B. F., Ruiz, C., 2012. Complementarity modeling in energy markets. Vol. 180. Springer Science \& Business Media.

GCF, 2014. The European Renewable Energy Investor Landscape.

URL http : //cleanenergypipeline.com/Resources/CE/ResearchReports/The\%20European\%20Renev

Gross, R., Blyth, W., Heptonstall, P., 2010. Risks, revenues and investment in electricity generation: Why policy needs to look beyond costs. Energy Economics 32 (4), 796-804.

Haas, R., Resch, G., Panzer, C., Busch, S., Ragwitz, M., Held, A., 2011. Efficiency and effectiveness of promotion systems for electricity generation from renewable energy sources lessons from EU countries. Energy 36 (4), 2186 - 2193, 5th Dubrovnik Conference on Sustainable Development of Energy, Water \& Environment Systems.

URL http : //www.sciencedirect.com/science/article/pii/S0360544210003518

Hardaker, J., Huirne, R., Anderson, J., Lien, G., et al., 2004. Coping with risk in agriculture, second edition. CABI Publishing.

Hern, R., Radov, D., Bermudez-Neubauer, M., Brejnholt, R., Huebler, D., Spasovska, M., Janeckova, Z., Tannenbaum, B., Fearnehough, H., 2013. Changes in hurdle rates for low carbon generation technologies due to the shift from the uk renewables obligation to a contracts for difference regime. Tech. rep., London: NERA Economic Consulting.

URL http : //www.nera.com/nera-files/20131209 ${ }_{N}$ ERA $_{R}$ eport $_{A}$ ssessment $_{o} f_{C}$ hange $_{i} n_{H}$ urdle $_{R}$ ates.p

Heydari, S., Ovenden, N., Siddiqui, A., 2012. Real options analysis of investment in carbon capture and sequestration technology. Computational Management Science 9 (1), 109-138.

URL http : //dx.doi.org/10.1007/s10287 - $010-0124-5$

Hirst, E., 2002. The financial and physical insurance benefits of price-responsive demand. The Electricity Journal 15 (4), 66-73. 
Hull, J. C., 2003. Options, Futures, and Other Derivatives. Pearson Prentice-Hall, London.

IEA and OECD, 2008. Deploying renewables principles for effective policies: in support of the G8 plan of action. IEA and OECD, Paris.

URL http : //www.myilibrary.com?id $=192197$

IWEA, 2011. The impact of wind on pricing within the Single Electricity Market.

URL http : //www.iwea.com/contentFiles/Documents\%20for\%20Download/Publications/News\%20 1298912434703

Kim, K.-K., Lee, C.-G., 2012. Evaluation and optimization of feed-in tariffs. Energy Policy 49, 192-203.

URL http : //linkinghub.elsevier.com/retrieve/pii/S0301421512004831

Kitzing, L., 2014. Risk implications of renewable support instruments: Comparative analysis of feed-in tariffs and premiums using a meanvariance approach. Energy 64, 495 - 505.

URL http : //www.sciencedirect.com/science/article/pii/S0360544213008414

Kitzing, L., Mitchell, C., Morthorst, P. E., Dec. 2012. Renewable energy policies in europe: Converging or diverging? Energy Policy 51, 192-201.

URL http : //linkinghub.elsevier.com/retrieve/pii/S030142151200746X

Klessmann, C., Rathmann, M., de Jager, D., Gazzo, A., Resch, G., Busch, S., Ragwitz, M., 2013. Policy options for reducing the costs of reaching the european renewables target. Renewable Energy 57, $390-403$.

URL http: //wWw. sciencedirect.com/science/article/pii/s0960148113000797

Leepa, C., Unfried, M., 2013. Effects of a cut-off in feed-in tariffs on photovoltaic capacity: Evidence fromgermany. Energy Policy 56, 536 - 542.

URL http://www. sciencedirect.com/science/article/pii/s0301421513000256

Loreck, C., Matthes, F., Hermann, H., Jung, F., Emele, L., Cook, V., 2012. Short analysis of the increase of the german EEG surcharge for 2013. Tech. rep., Berlin: ko-Institut e.V.

URL http : //www.oeko.de/oekodoc/1607/2012 - 461 - en.pdf

Ma, C.-T. A., McGuire, T. G., 1997. Optimal health insurance and provider payment. The American Economic Review 87 (4), pp. 685-704.

URL http: //WwW.jstor.org/stable/2951369

Mahul, O., 2001. Optimal insurance against climatic experience. American Journal of Agricultural Economics 83 (3), pp. 593-604.

URL http: / / www.jstor.org/stable/1245089 
Mc Garrigle, E., Deane, J., Leahy, P., 2013. How much wind energy will be curtailed on the 2020 Irish power system? Renewable Energy 55, 544-553.

URL http : //linkinghub.elsevier.com/retrieve/pii/S0960148113000384

Menanteau, P., Finon, D., Lamy, M.-L., Jun. 2003. Prices versus quantities: choosing policies for promoting the development of renewable energy. Energy Policy 31 (8), 799-812.

URL http : //linkinghub.elsevier.com/retrieve/pii/S0301421502001337

Meyer, D., Meyer, J., 2005. Relative risk aversion: What do we know? Journal of Risk and Uncertainty 31 (3), 243-262.

URL http://dx.doi.org/10.1007/s11166-005-5102-x

Nahmmacher, P., Schmid, E., Hirth, L., Knopf, B., 2014. Carpe diem: a novel approach to select representative days for long-term power system models with high shares of renewable energy sources.

Neuhoff, K., Bach, S., Diekmann, J., Beznoska, M., El-Laboudy, T., 2013. Distributional effects of energy transition: impacts of renewable electricity support in Germany. Economics of Energy \& Environmental Policy 2 (1).

Parkinson, S. C., Djilali, N., 2015. Long-term energy planning with uncertain environmental performance metrics. Applied Energy 147, $402-412$.

URL http://www. sciencedirect.com/science/article/pii/s0306261915001646

Pindyck, R., 1999. The long-run evolution of energy prices. Energy Journal 20 (2), 1-27.

Pinkdyck, R. S., 2001. The dynamics of commodity spot and futures markets: A primer. Energy Journal 22 (3), 1.

Pratt, J. W., 1964. Risk aversion in the small and in the large. Econometrica 32 (1/2), pp. 122-136. URL http: / / wWw.jstor.org/stable/1913738

Ragwitz, M., Held, A., Resch, G., Faber, T., Haas, R., Huber, C., Coenraads, R., Voogt, M., Reece, G., Morthorst, P., Jensen, S., Konstantinaviciute, I., Heyder, B., 2007. Assessment and Optimization of Renewable Energy Support Schemes in the European Electricity Market: Final Report. Optimization of Renewable Energy Support (OPTRES) project for the European Commission, DG TREN, and Intelligent Energy for Europe (IEE), Karlsruhe, Germany.

Raviv, A., 1979. The design of an optimal insurance policy. The American Economic Review 69 (1), pp. 84-96.

URL http: / / www.jstor.org/stable/1802499 
Riesz, J., Vithayasrichareon, P., MacGill, I., 2015. Assessing gas transition pathways to low carbon electricity - An Australian case study. Applied Energy 154, 794 - 804.

URL http://www. sciencedirect.com/science/article/pii/s0306261915007047

Ringel, M., 2006. Fostering the use of renewable energies in the European Union: the race between feed-in tariffs and green certificates. Renewable Energy 31 (1), 1 - 17.

URL http : //www.sciencedirect.com/science/article/pii/S0960148105000789

Sadorsky, P., 2012. Modeling renewable energy company risk. Energy Policy 40, 39-48.

Schwartz, E., Smith, J. E., 2000. Short-term variations and long-term dynamics in commodity prices. Management Science 46, 893-911.

SEAI, 2011. SEAI wind energy roadmap 2011-2050. Report of the SEAI Energy Modelling Group.

SEMO, 2015. SEMO value of market. Tech. rep.

URL http : //www.sem - o.com/pages/MDB $B_{V}$ alueOf Market.aspx

Sensfuß, F., Ragwitz, M., Genoese, M., 2008. The merit-order effect: A detailed analysis of the price effect of renewable electricity generation on spot market prices in Germany. Energy Policy 36 (8), 3086-3094.

URL http : //linkinghub.elsevier.com/retrieve/pii/S0301421508001717

Siddiqui, A., Fleten, S.-E., 2010. How to proceed with competing alternative energy technologies: A real options analysis. Energy Economics 32 (4), 817 - 830.

URL http: //www.sciencedirect.com/science/article/pii/s0140988309002473

Siddiqui, A. S., Maribu, K., 2009. Investment and upgrade in distributed generation under uncertainty. Energy Economics 31 (1), 25 - 37.

URL http://www. sciencedirect.com/science/article/pii/s0140988308001187

Siddiqui, A. S., Tanaka, M., Chen, Y., 2016. Are targets for renewable portfolio standards too low? the impact of market structure on energy policy. European Journal of Operational Research 250 (1), 328-341.

SSE, 2015. Providing the energy people need SSE plc annual report 2015. Tech. rep.

URL http : //sse.com/media/332715/SSE_AR2015_6Aug_UPDATE.pdf

Verde, S. F., Pazienza, M. G., 2013. Cost recovery of RES-E support in Italy: A new case for a carbon tax. EUI Working Paper RSCAS 2013/72European University Institute Robert Schuman Centre for Advanced Studies, Climate Policy Research Unit, Florence. 
von Neumann, J., Morgenstern, O., 1947. The Theory of Games and Economic Behavior. Princeton University Press.

Wakker, P. P., 2008. Explaining the characteristics of the power (crra) utility family. Health economics 17 (12), 1329-1344.

Wickart, M., Madlener, R., 2007. Optimal technology choice and investment timing: A stochastic model of industrial cogeneration vs. heat-only production. Energy Economics 29 (4), 934 952, modeling of Industrial Energy Consumption.

URL http://www. sciencedirect.com/science/article/pii/s0140988306001484

Willems, B., Morbee, J., 2010. Market completeness: How options affect hedging and investments in the electricity sector. Energy Economics 32 (4), 786 - 795, policymaking Benefits and Limitations from Using Financial Methods and Modelling in Electricity Markets.

URL http: //wWw. sciencedirect.com/science/article/pii/s0140988309002023

Wogrin, S., Galbally, D., Reneses, J., 2016. Optimizing storage operations in medium-and longterm power system models. IEEE Transactions on Power Systems 31 (4), 3129-3138.

Wogrin, S., Gayme, D. F., 2015. Optimizing storage siting, sizing, and technology portfolios in transmission-constrained networks. IEEE Transactions on Power Systems 30 (6), 3304-3313.

Yang, M., Blyth, W., 2007. Modeling investment risks and uncertainties with real options approach. International Energy Agency.

Zhang, Q., Wang, X., Aug 2009. Hedge contract characterization and risk-constrained electricity procurement. Power Systems, IEEE Transactions on 24 (3), 1547-1558.

Zhu, L., 2012. A simulation based real options approach for the investment evaluation of nuclear power. Computers \& Industrial Engineering 63 (3), 585-593. 